University of Zurich

Department of Economics

Working Paper Series

ISSN 1664-7041 (print)

ISSN 1664-705X (online)

Working Paper No. 102

\title{
'By a Silken Thread': regional banking integration and credit reallocation during Japan's Lost Decade
}

Mathias Hoffmann and Toshihiro Okubo

Revised version, May 2021 


\title{
'By a Silken Thread': regional banking integration \\ and credit reallocation during Japan's Lost Decade*
}

\author{
Mathias Hoffmann, University of Zurich ${ }^{\dagger}$ \\ Toshihiro Okubo, Keio University
}

May 2021

\begin{abstract}
A key benefit from banking integration is that it allows credit to be reallocated to regions with high credit demand. Using the natural experiment of Japan's lost decade, we show that this reallocation channel mitigated the real effects from the bank liquidity shock in prefectures with many bank-dependent SMEs. To account for the potential endogeneity of banking integration, we exploit the fact that regional segmentation of banking markets in Japan goes back to the institutions set up for silk export finance in the late 19th century. Using silk as an instrument for modern-day regional banking integration, we illustrate how the bias of the OLS estimate can provide information about unobserved cross-regional heterogeneity in bank-firm matches when only aggregate regional data is available. Our results highlight that well-integrated banking markets are important and complementary to bond markets in limiting macroeconomic asymmetries in a monetary union, in particular during major financial crises.
\end{abstract}

JEL-Codes: F36, F40, G01, N15, N25

KEY WorDs: Japan; Lost Decade; banking integration; regional business cycles; transmission of financial shocks; bank lending channel; firm-borrowing channel; reallocation channel; internal capital markets; monetary union;

\footnotetext{
${ }^{*}$ We are grateful for comments from two anonymous referees, Kenji Aramaki, Thorsten Beck, Sascha Becker, Daniel Bernhofen, Fabio Braggion, Linda Goldberg, Pierre-Olivier Gourinchas, Tarek Hassan, Takeo Hoshi, Sebnem Kalemli-Ozcan (the editor), Asim Khwaja, Alexander Ljungqvist, Masaki Nakabayashi, Joe Peek, Bent Sorensen, Pascal Towbin, Wako Watanabe, Frank Westermann, Hirofumi Uchida, Iichiro Uesugi which greatly helped improve the paper. The paper also benefited from the feedback of seminar and conference participants at the Asian-Pacific Research Center at Stanford University, the Banca d'Italia, University of Bonn, Hitotsubashi University, Keio University, RIETI, University of Muenster, University of Osnabrück, University of Tübingen, Deutsche Bundesbank, the University of Zurich, the Austrian National Bank, EEA-ESEM, the CEPR workshop 'Economics of cross-border banking' in Paris, the NBER Japan Project meeting in Tokyo, at National University of Singapore, and the Japan Economy Network conference in Zurich.

${ }^{\dagger}$ University of Zurich, Dept. of Economics, Zürichbergstrasse 14, CH-8032 Zurich / Switzerland. E-mail: mathias.hoffmann@econ.uzh.ch Web: http://www.mathiashoffmann.net. Hoffmann is also affiliated with the Research Priority Program in Financial Regulation (URPP FinReg) at University of Zurich, CESifo Munich and the Centre for Applied Macroeconomic Analysis (CAMA) at Crawford School of Public Policy, Australian National University.

${ }^{\ddagger}$ Keio University, 2-15-45 Mita Minato-ku Tokyo,108-8345 Japan. E-Mail: okubo@econ.keio.ac.jp
} 


\section{Introduction}

The possibility to reallocate credit to arbitrage geographical differences in the demand for credit is one of the major benefits from banking integration. This paper uses the Japanese lost decade of the 1990s as a natural experiment to show that the geographical reallocation of credit by regionally integrated banks limits macroeconomic asymmetries between the member regions of a monetary union during a major banking crisis.

In the early 1990s Japan saw the bust of a major real estate bubble. This bubble was particularly prickly in the big cities such as Tokyo or Osaka where it was predominantly financed by credit from big banks operating nationwide or at least in large parts of the country (to which we refer as integrated banks). When real estate markets crashed the burst was most dramatic in the big cities, thus affecting the balance sheets of integrated banks more than those of most local banks. At the same time, Japan's banking market-for regulatory and historical reasons that we will discuss in detail—was highly segmented along regional lines, with local banks mainly financing the activities of local small and medium sized manufacturing enterprises (SME) for which bank credit is often the only source of external finance.

We exploit variation across Japanese prefectures in both regional banking integration (measured as the market share of integrated banks in local (i.e. prefecture-level) lending) and local firms' dependence on bank credit to study how Japan's bursting real estate bubble of the 1990s was transmitted to regional economies (prefectures) across the country.

Our key empirical result is that—amid a general retrenchment in lending-geographically integrated banks lent relatively more in prefectures with many credit-dependent SMEs. This substantially mitigated the adverse real effects of the banking crisis on these prefectures and contributed to reducing the cross-regional heterogeneity in output responses. We show this pattern to be consistent with a stylized model in which internal capital markets allow nationwide banks to react to regional differences in loan demand by reallocating credit to prefectures where it was most urgently needed-by small, bank-dependent firms that cannot easily substitute locally issued loans for alternative sources of finance from outside their prefecture. 
We call this the credit reallocation channel.

To the best of our knowledge, the credit reallocation channel and, in particular, its role in providing effective macroeconomic risk sharing has not been previously studied in the literature. ${ }^{1}$ We therefore believe that our results have implications-beyond the specific context of Japan's lost decade-for the literature on international banking more generally. First, our findings suggest that neglecting to control for the reallocation of credit by integrated banks to the most credit-dependent customers may lead to inflated (negative) estimates of the real effects of banking shocks and an underestimate of the extent to which integrated banking markets provide macroeconomic risk sharing between countries or regions-even, and in particular, during a banking crisis. Secondly, while the international banking literature-that we survey in the next section-has documented the operation of banks' internal capital markets, to our knowlegde, it has not systematically examined if geographical credit reallocation during a banking crisis is consistent with simple macroeconomic models of banking and whether it actually helps mitigate real asymmetries between countries or between the regions of a country. Third, our findings also illustrate an important complementarity between bond markets and regionally integrated banking markets in providing macroeconomic risk sharing among the regions of a monetary union. The credit reallocation channel implies that bank shifted credit towards regions with many inelastic borrowers, i.e. bank-dependent SMEs. This attenuated the real effects of the banking crisis in the high-SME regions. Conversely, output in low-SME regions was stabilized because elastic borrowers (big firms) could make up for the reduction in bank lending by issuing more bonds.

Our results raise the question how and why in Japan's generally highly integrated national economy, regional differences in banking integration could be so persistent as to affect the regional spread of a major crisis across the country for the best part of the 'lost decade. Here

\footnotetext{
${ }^{1}$ Throughout the paper we refer to macroeconomic risk sharing in a broad sense as mechanisms that limit the asymmetry of output shocks. In this respect our terminology differs from the literature on macroeconomic consumption risk sharing which tends to focus on mechanisms that help limit the fallout of asymmetric output shocks on consumption. For prominent examples of this strand of the literature see Asdrubali et al. (1996) and Kalemli-Ozcan et al. (2003).
} 
we build on a historical companion paper (Hoffmann and Okubo (2021)) in which we argue that the de facto regional segmentation of Japan's banking market has long-standing historical origins. Specifically, prefectures in which silk reeling emerged as the first main export industry in the late 19th century developed a particular system of export finance in which regional, cooperative or mutual banks came to play a key role in local banking markets. To the present day, the silk regions have a high market share of local banks which predominantly engage in long-term lending relationships with their predominantly SME customers. For many of these bank-dependent firms these persistent bank-firm relationships were virtually impossible to switch in the years after 1990.

We exploit this historical background to overcome potential challenges to identification in our baseline reduced-form specifications. Using measures of the local importance of silk reeling in 1895 as an instrument for modern-day regional banking integration strengthens our findings regarding the importance of the reallocation channel. It also provides us with a way to assess how our use of aggregate regional data instead of micro bank-firm level data affects our results. Specifically, we discuss that the sign of the difference between the IV and the OLS estimate is informative with respect to an important conjecture underlying our mechanism: in regions with a high market share of city banks, the firms most affected by the crisis (i.e. SMEs) should be more likely to be linked to the banks with the highest exposure to the land price decline (i.e integrated banks). If this is the case, OLS estimates will be biased towards zero. Our IV estimates show that this is indeed the case, consistent with the unobserved heterogeneity in bank-firm relationships that is implied by our theory. Hence, the IV approach helps us at least partially overcome the lack of matched firm-bank level data with sufficient spatial coverage and thus puts us into a position to make statements about the geographical dimension of Japan's lost decade. Our approach therefore allows to evaluate potential challenges to the identification of liquidity shocks in settings where data are only available at a relatively high level of aggregation-as will often be the case in cross-country or cross-regional studies in international economics. 


\section{Contribution to the literature}

Our point of departure is the literature on banking crises and international business cycle transmission. Early classic contributions in this literature already used the bursting of Japan's big property and stock market bubbles of the 1980s as an identifying shock to banks' lending behavior. Peek and Rosengren $(1997,2000)$ were the first to document how this shock to the balance sheet of Japanese banks affected economic activity in local U.S. banking markets. More recently, Imai and Takarabe (2011) find that more financially integrated prefectures were more exposed to the property price downturn in the big cities via the bank-lending channel. We follow their method to identify the shock to nationwide banks' lending supply, but, importantly, we extend it to take account of the reallocation channel. We also contribute a regional perspective to the literature on banking crises and financial integration (Dell'Ariccia et al. (2008) and Kroszner et al. (2007)). These studies examine the aftermath of banking crises in a large cross section of countries. Our focus here is on the regional heterogeneity in responses to a common (country-wide) shock over time.

The stylized model in which we derive the reallocation channel directly extends the framework of Morgan et al. (2004). Importantly, we allow for differences in credit dependence (captured by different elasticities of credit demand) across local markets. This extension implies that the effects of a country-wide negative lending supply shock on lending will differ across regions, with more bank dependent regions seeing smaller declines in bank lending. Morgan et al. (2004) use their framework to explore the impact of U.S. state-level banking integration on business cycle synchronization, concluding that state-level liberalization predominantly provides insurance against idiosyncratic credit supply shocks. At the international level, Kalemli-Ozcan et al. (2013b) show that higher banking integration tends to be associated with lower business cycle synchronization, which suggests that asymmetric credit demand shocks dominate in international data. While the focus of these papers is on how financial integration affects the transmission of asymmetric banking shocks in tranquil periods, our analysis here examines the role of banking integration during a major aggregate 
shock to bank lending. In this respect, we closely relate to Kalemli-Ozcan et al. (2013a) who provide evidence and a quantitative model showing that banking integration leads to higher business cycle synchronization mainly in crisis times. In addition, however, our analysis here also allows to distinguish between two different potential sources of synchronization during a major banking crisis: the reallocation of credit between regions with different borrowing needs (the reallocation channel) or the common exposure of regions to common lenders (integrated banks) affected by the shock (the bank lending channel). Our results suggest that credit reallocation (and not the common exposure of prefectures to crisis-hit integrated banks) was the main driver of regional business cycle synchronization in Japan during the lost decade.

The important role of the reallocation channel that we document here suggests that internal capital markets played a key role in explaining cross-prefectural differences in credit supply by integrated banks during Japan's crisis. In the international banking literature, de Haas and van Lelyveld (2010) is an early contribution documenting that multinational banks do indeed operate internal capital markets across countries. Cetorelli and Goldberg (2012a,b) show that the internal liquidity management of US banks played a key role in the international transmission of the 2008 financial crisis and that banks tended to redirect lending to their core destination markets. Giannetti and Laeven (2012) document a 'flight home' effect, showing that banks bias their lending towards domestic markets during a financial crisis. De Haas and Van Horen (2013) show that following the Lehman shock, banks retrenched less from geographically close foreign markets and from markets in which they were long established.

One key insight emerging from this literature is that the retrenchment of international banks from foreign markets during crises is clearly not uniform. Rather, it depends on the characteristics of the destination market, and the importance of this market in the bank's lending portfolio. Our results are consistent with these findings and complement them in several ways. One interesting aspect of our results is that similarly heterogenous lending responses during a crisis can be observed across the regions of a single country where regions 
are highly integrated from an institutional, political and regulatory perspective. Our analysis here also goes beyond the earlier literature by showing that the heterogeneity of these responses is consistent with a simple model in which integrated banks allocate funds in a profit-maximizing manner across destination markets in which they face different elasticities of credit demand. Furthermore, we innovate by looking at the aggregate real effects of credit reallocation on region-level output and at the role of role of reallocation in dampening cross-regional heterogeneity in business cycles ${ }^{2}$

We also relate closely to research that uses matched bank-firm level data to study the impact of bank liquidity shocks. Khwaja and Mian (2008) were the first to use such data and find that lending to the same firm by banks with higher exposure to a liquidity shock is affected more (the bank lending channel). However, the real effects from reduced lending are mainly due to smaller firms that cannot tap alternative sources of credit (the firm-borrowing channel). Giannetti and Simonov (2013) use a similar approach and a sample of large listed firms to study the real effects of bank recapitalizations in Japan. Hosono et al. (2016) find that bank liquidity shocks after the Kobe earthquake negatively affect client firms' investment even in a highly developed market such as Japan. Ongena et al. (2015) document that during the Lehman crisis, foreign-owned and internationally borrowing domestic banks cut their credit in Eastern Europe more strongly than domestically financed banks and that this disproportionately affected the real performance of SMEs. Schnabl (2012) shows that the liquidity shock of the 1998 Russian default led to a decline in cross-border interbank lending to Peruvian bank's which in turn reduced lending to their local borrowers. Baskaya et al. (2017) document how international capital inflows affect the credit supply of domestic banks in Turkey.

None of the bank-firm level studies above looks at the reallocation of credit across ge-

\footnotetext{
${ }^{2}$ Gilje et al. (2016) and Cortés and Strahan (2017) illustrate the working of internal capital market in intranational U.S. bank-level data. Both papers focus on the impact on integrated banks of region-specific shocks to credit demand and supply respectively. Our emphasis here is on how a large negative country-wide bank liquidity shock affects the geographic allocation of bank credit and, importantly, how reallocation helps limit regional heterogeneity in real outcomes.
} 
ographic locations and at how this helps in mitigating the heterogeneity in real outcomes. This is one important dimension along which we add with this paper. We show that the negative real effects that arise from the inability of small firms to switch to alternative sources of finance (the firm-borrowing channel) are considerably dampened through the geographical reallocation of credit by country-wide banks. The only recent paper we are aware of that looks at credit reallocation using bank-firm level data is De Jonghe et al. (2020) who show that after a funding shock banks reallocate credit towards sectors in which they have high market share or in which they specialize. However, this study also does not look at the macroeconomic and geographical dimension of reallocation nor does it investigate its role in sharing business cycle risk among regions, as we do here.

Our findings in this paper also speak to the complementarity of bond (i.e. capital market) and bank finance in limiting economic asymmetries in a monetary union-a topical debate in the context of European Monetary Union (EMU) (Constâncio (2017); Hoffmann et al. (2019); Martinez et al. (2019)). The reason why the reallocation of bank credit from a region with many elastic borrowers ("big firms") to a region with many inelastic borrowers ("small firms") stabilizes output in both regions is that the reduction of bank credit to big firms has only small output effects because big firms can easily substitute bank credit with bond finance (Chava and Purnanandam (2011)). As we discuss, the bank credit crunch during Japan's lost decade was accompanied by an increase in net bond issuance by big Japanese corporates (Hoshi (1995); Hoshi and Kashyap (2004)). Hence, bond finance freed up funds in a stressed banking system that could more efficiently be allocated to the most bank-dependent firms. Local banks with their relationship-based business model are generally seen as having a comparative advantage in lending to small, relatively opaque firms (Berger et al. (2005); Stein (2002)). Japan’s local, cooperative banks are prime examples in this respect (Uchida et al. (2008)). However, our results here highlight that small and medium-sized firms are also among the prime beneficiaries of banking integration, a finding that is consistent with the evidence from U.S. banking deregulation in the 1980s (Demyanyk et al. (2007), Rice and Strahan (2010), Hoffmann and 


\section{Shcherbakova-Stewen (2011)) and from Eastern Europe (Giannetti and Ongena (2007)). ${ }^{3}$}

Admittedly, our focus on the regional macroeconomic effects of credit reallocation comes at a price. Only matched bank-firm level data would ultimately allow to put the mechanism under the microscope. However, as is the case for Japan's lost decade, such data are often not available over long historical periods, nor is their geographic coverage usually sufficient to warrant macroeconomic statements about the spatial dimension of a crisis and its mediumterm repercussions. Hence, we face a classical trade-off between internal and external validity.

To alleviate potential threats to identification in our region-level analysis, we proceed in two steps. First, we address the endogeneity of regional banking market integration using an instrument motivated from economic history. ${ }^{4}$

Secondly, we interpret the difference between the OLS and the IV estimate to check the plausibility of our conjectured mechanism. To see the gist of our argument, assume that economic theory suggests how OLS-estimates based on regional data are affected by unobserved cross-regional heterogeneity in the matches between banks and firms. Using an instrument we can then check the sign of the bias and thus shed light on whether the heterogeneity in bank-firm level matches is consistent with theory. In the context of Japan's lost decade our theory and the historical background suggest that in highly integrated prefectures with many SMEs, the firms most vulnerable to a decline in local demand (SMEs) were also most likely to be linked to the type of bank most affected by the property market crash. We show that OLS-estimates of the reallocation effect will be biased towards zero in this setting and confirm this with our IV estimates. The methodological contribution of the paper therefore is how to evaluate the significance of potential challenges to identification of liquidity shocks in settings where matched bank-firm data are not available.

\footnotetext{
${ }^{3}$ Along the same lines, Bord et al. (2018). document that big U.S. Banks have moved into SME lending following the great financial crisis of 2008/09, as banks started to withdraw from mortgage lending following tighter regulation and low interest rates provided top-rated big corporates with excellent conditions for bond issuance.

${ }^{4}$ See our companion paper Hoffmann and Okubo (2021), Nakabayashi (2001, 2006, 2014), and Miwa and Ramseyer (2006) for the historical background.
} 


\section{Regional banking integration and crisis transmission}

\subsection{Theoretical considerations}

Figure (1) presents a stylized version of a banking model in the spirit of Holmstrom and Tirole (1997) that we adapt from Morgan et al. (2004). We assume that there are two prefectures and three banks: two equally sized local banks, each of which operates in one of the two prefectures only and one integrated bank operating in both prefectures. The integrated bank operates an internal capital market which allows it to reallocate credit between prefectures. Profit maximization by the integrated bank then implies that the interest rate charged on the marginal loan in each prefecture is equalized.

To formalize the notion that SMEs cannot easily borrow from banks outside the prefecture or from the bond market, we assume that the loan demand of SMEs is less elastic with respect to loan interest rates than that of big firms. ${ }^{5}$ We further assume that local banks specialize in lending only to SMEs (very much in keeping with the actual situation in Japan that we present in more detail below) while the integrated bank generally lends to both SMEs and big firms. The left panel of the figure illustrates the case of a prefecture with a small share of SMEs, and the right panel illustrates the case of a prefecture with many SMEs. The demand curve of the city bank in the low-SME prefecture is flatter than the one faced by the regional bank because the local bank only lends to SME customers, whereas the city bank lends to big firms. ${ }^{6}$

Consider now a countrywide land price decline that forces both the local and the integrated banks to reduce their countrywide loan supply by an amount $\overline{\Delta L}$. Suppose at the

\footnotetext{
${ }^{5}$ Hoshi and Kashyap (2000) show that SMEs in the manufacturing sector kept their bank-debt-to-asset ratios of around 30-35 percent largely constant during the 1980s and 1990s. By contrast, big manufacturing firms switched to the bond market, thus considerably lowering this ratio during the 1990s to levels of well below 20 percent on average. Also, since bank loans in Japan traditionally are secured by collateral (mainly land), banks' credit provision to SMEs is likely to be particularly dependent on fluctuations in local land values (see Gan (2007)).

${ }^{6}$ For expositional simplicity, we assume that the integrated bank does not lend to SME customers in the low-SME prefecture while there are no big firms in the high-SME prefecture so that both the city and the local bank face only demand from SMEs in the high-SME prefecture.
} 
outset that both local and integrated banks have the supply curve $L_{0}$ and that both types of banks lend to their customers at rate $r_{0}$. As we assumed all local banks to be equal (and, therefore, equally hit by the shock), each of them will reduce its loan supply by $\overline{\Delta L} / 2$, as illustrated by the shift from $L_{0}$ to $L_{\text {local }}$ in the two panels. By contrast, the integrated bank operates an internal capital market across prefectures and will therefore allocate loans such that the interest rate on the marginal loan in each prefecture is equalized. Therefore, it will reduce its lending by less than $\overline{\Delta L} / 2$ in the high-SME prefecture and by more than $\overline{\Delta L} / 2$ in the low-SME prefecture, as shown in the shift from $L_{0}$ to $L_{C i t y}$ in the respective panel.

This is the key empirical implication that we test in the remainder of the paper: conditioning on the size of the negative bank liquidity shock, a high-SME region will see a less marked reduction in lending (and to the extent that lending drives GDP through the firm-borrowing channel, also a higher GDP growth rate) if it is financially integrated. We call this effect the credit reallocation channel. Via their internal capital markets, integrated banks respond to cross-prefectural differences in bank dependence by allocating relatively more credit to the most bank-dependent prefectures (where the willingness to pay for credit is highest) until the interest rate on the marginal loan is equalized across locations.

We make the following remarks: First, our exposition in in Figure (1) assumes that SMEs that have borrowed from a local bank cannot easily switch to borrowing from an integrated bank in the same prefecture to take advantage of the lower lending rates offered by the integrated bank - at least not in the short run. This assumption is likely to be justified empirically because the tight relationships in Japan between local banks and SMEs are likely to create a holdup problem that effectively segments the banking market within the prefecture (Sharpe (1990); Rajan (1992)). We would expect that the extent of the hold-up faced by the average SME in a prefecture to depend on the degree of banking integration itself: in high-SME prefectures with high financial integration it is likely that a big share of SMEs already bank with integrated banks at the outset. Also, if integrated banks have a strong local presence, we would expect that it is easier for an SME to switch to an integrated bank. Below, we provide evidence 
that supports both of these conjectures.

Secondly, our exposition in Figure (1) assumes that the liquidity shock affects both the integrated and the local banks equally. It is well documented in the literature that during Japan's lost decade, city (i.e. integrated) banks were hit more strongly than regional (i.e. local) banks because their exposure to the big cities, where property prices declined most strongly was much higher than that of most local banks (Imai and Takarabe (2011). The integrated banks are therefore likely to have reduced lending by more than the local bank overall. We emphasize that this does not matter for the the reallocation effect: the theory implies that integrated bank would still preserve relatively higher levels of lending in high-SME prefectures. Econometrically, this means that the reallocation effect will be identified from a double difference-in-difference specification (i.e. the double difference between high- and low- integration and high-SME and low-SME prefectures). Our econometric specifications throughout the paper therefore explicitly allow for the possibility that local and integrated banks are affected asymmetrically by the burst of the land price bubble.

Third,we emphasize that the simple theory helps identify whether the burst of Japan's land price bubble was predominantly a credit supply or a credit demand shock. The reason for this is that the reallocation channel will have opposite signs depending on whether the shock is to credit supply or to credit demand. As we illustrate in Figure A.1 in the appendix, a common negative shock to credit demand would, on impact, lead to larger drop in the interest rate in the high-SME region where demand is the least elastic. Therefore, integrated banks will reallocate credit away from these areas to use it to expand credit-supply in the regions with the most elastic demand, thus equalizing interest rates on their marginal loans in the two prefectures. Hence, while all our econometric specifications also include additional controls for differences in local credit demand, our finding that the coefficient on the double difference-indifference between high/low SME and high/low financial integration prefectures are positive across all specifications in the paper provides an important independent corroboration that Japan’s bursting land price bubble was indeed predominantly a credit-supply shock. 


\subsection{Econometric framework and identification}

To obtain an exogenous measure of bank loan supply, we build on the literature (Peek and Rosengren (1997)) and interpret the decline of Japan's real estate market as an exogenous shock to the balance sheet of the banking sector. In particular, we follow Imai and Takarabe (2011) who argue that integrated banks were more exposed to the land price decline in the major cities than local banks (at least those outside the major cities). We therefore use the average land price decline in the core prefectures (the greater Tokyo area, comprising of Tokyo, Kanagawa, Saitama and Chiba Prefectures) as well as Aichi (with Nagoya), Osaka, Hyogo (with Kobe) and Kyoto prefectures) as our main measure of the shock. We code the bank liqudity shock SHOCK$_{t}$ as the negative of the core land price growth, so that

$$
\text { SHOCK }_{t}=- \text { LANDPRICEGROWTH in } \mathrm{CORE}_{t}
$$

This normalization ensures that all of our main coefficients of interest are positive and easy to compare and interpret in our subsequent discussions: conditional on the negative bank liquidity shock, the credit reallocation channel should lead to relatively higher growth rates in lending and real economic activity.

The credit reallocation channel implies that integrated banks take advantage of differences in loan demand elasticities between prefectures to maximize profits. We index the elasticity of loan demand by the share of small firms in the local economy. Also, based on our model above, credit reallocation should be stronger in more integrated prefectures. Based on these considerations we posit the following supply equation for the growth of (log) bank lending, $\Delta$ Lending, in prefecture $k$ :

$$
\Delta \text { Lending }_{t}^{k}=\left[\beta_{0} \mathrm{SME}^{k}+\beta_{1}\right] \times \mathrm{FI}^{k} \times \mathrm{SHOCK}_{t}+\xi_{t}^{k}
$$

where $\mathrm{SME}^{k}$ and $\mathrm{FI}^{k}$ denote, respectively, the (pre-crisis) share of small firms in employment 
or output and the (pre-crisis) share of integrated banks in total lending in prefecture $k$. The term $\xi_{t}^{k}$ captures prefecture-specific lending supply factors, including the lending supply by local banks.

In this equation, $\beta_{0}$ captures the credit reallocation channel whereas $\beta_{1}$ indexes the strength of the classical bank-lending channel. We would expect that in the Japanese case, $\beta_{1}<0$ : in more integrated prefectures lending growth was lower after the shock.

Importantly, however, the impact of the aggregate liquidity shock should not only be scaled by a prefectures exposure to aggregate shock (as measured by FI), but also by the local elasticity of demand, as indexed by SME. Our theory makes sharp predictions about how the nature of the aggregate shock affects the sign of the coefficient $\beta_{0}$ and thus the direction of this credit reallocation channel: if $\mathrm{SHOCK}_{t}>0$ captures a negative loan supply shock, then the discussion in the previous section would imply that $\beta_{0}>0-$ in response to a negative aggregate loan supply shock, integrated banks will maintain relatively higher levels of lending in high-SME prefectures. Conversely, as discussed above, it is easy to see from the model that $\beta_{0}<0$ will hold if SHOCK $_{t}>0$ codes a negative aggregate loan demand shock. In this case, integrated banks would withdraw more strongly from high-SME prefectures after a negative aggregate demand shock. ${ }^{7}$ Based on our earlier discussion, our focus is on the supply shock scenario and we therefore expect $\beta_{0}>0$.

Our ultimate interest is in identifying how credit reallocation dampened the effects of the banking liquidity shock on regional economic activity. To link fluctuations in bank lending to output growth, we conjecture that

$$
\Delta \operatorname{GDP}_{t}^{k}=\gamma \times \Delta \text { Lending }_{t}^{k}+\eta_{t}^{k}
$$

\footnotetext{
${ }^{7}$ The literature has predominantly interpreted the burst of Japan's real estate bubble as a shock to loan supply. Our empirical results very strongly support that $\beta<0$ and are therefore consistent with this interpretation. However, our theory does not a priori require us to take a stand on the nature of the shock. As long as we accept the view that the burst of Japan's real estate bubble was a negative shock to lending, the sign of $\beta$ will allows us to identify the prevalent nature - loan demand or supply - of the shock from the perspective of the integrated bank.
} 
where $\Delta \operatorname{GDP}_{t}^{k}$ a is the growth rate of GDP in prefecture $k$ and $\eta_{t}^{k}$ is a productivity shock for firms in region $k$. The coefficient $\gamma$ captures the firm-borrowing channel (Khwaja and Mian (2008)): if $\gamma=0$ firms can fully offset variations in loan supply, e.g. by obtaining credit from banks in other regions or countries or by turning to internal finance or non-bank finance, e.g. by issuing bonds. If $\gamma>0$, then fluctuations cannot be fully offset and have real effects.

Estimating regression (3) by OLS will lead to estimates that are biased upwards. Within prefectures, the productivity shock $\eta_{t}^{k}$ will generally be positively correlated with the demand component of lending growth. To see how our approach solves this identification problem, we plug the lending supply equation into the reduced-form equation for GDP-growth (3), so that

$$
\Delta \operatorname{GDP}_{t}^{k}=[\underbrace{\gamma \times \beta_{0} \times \mathrm{SME}^{k} \times \mathrm{FI}^{k}}_{\text {firm-borrowing } \times \text { credit-reallocation }}+\underbrace{\gamma \times \beta_{1} \times \mathrm{FI}^{k}}_{\text {firm-borrowing } \times \text { bank-lending }}] \times \mathrm{SHOCK}_{t}+\psi_{t}^{k}
$$

where $\psi_{t}^{k}=\eta_{t}^{k}+\gamma \times \xi_{t}^{k}$ absorbs prefecture-specific influences on GDP coming from lending supply $\left(\xi_{t}^{k}\right)$ as well as from local demand or productivity factors $\eta_{t}^{k}$. The second term in parentheses describes the classical interaction between the bank-lending and the firm borrowing channels emphasized by the earlier literature. The first term is the focus of our attention here: it tells us how credit-rellocation by integrated banks attenuates the real fallout from the shock.

Based on (2) and (4), our reduced-form specifications will be of the general form

$\operatorname{OuTCOME}_{t}^{k}=\left[\alpha_{0} \times \mathrm{SME}^{k} \times \mathrm{FI}^{k}+\alpha_{1} \times \mathrm{FI}^{k}+\alpha_{2} \times \mathrm{SME}^{k}+\boldsymbol{\alpha}_{3}^{\prime} X^{k}\right] \times \mathrm{SHOCK}_{t}+\mu^{k}+\tau_{t}+\boldsymbol{b}^{\prime} Z_{t}^{k}+\nu_{t}^{k}$

where OUTCOME stands, in turn for prefecture-level lending or GDP. This empirical specification allows aggregate shock to affect local output or lending growth via additional prefecturelevel characteristics, summarized in the vector $X^{k}$. Specifically, we also include the interaction $\mathrm{SME}^{k} \times \mathrm{SHOCK}_{t}$ to capture effects of the burst of the bubble that could affect prefectures 
with more SMEs through other channels than integrated banks' lending. $Z_{t}^{k}$ is a vector of additional controls that may vary by time and prefecture, and $\boldsymbol{b}$ is the associated vector of coefficients. The terms $\mu^{k}$ and $\tau_{t}$ are prefecture-fixed and time effects, respectively, and $\nu_{t}^{k}$ is the error term.

Identification Regression (5) is a double differences-in-differences (DiD) specification in which the interactions with the intervention $\left(\mathrm{SHOCK}_{t}\right)$ vary only by prefecture $(k)$ and not by time. This approach emphasizes the spirit of our analysis: we do not claim that shortterm, year-to-year fluctuations in financial integration or small-business importance affect post-1990 prefecture-level outcomes. In fact, we use pre-1990 characteristics to eliminate short-term feedback effects of growth on financial integration or the share of small businesses in the prefectural economy from our analysis. Bertrand et al. (2004) strongly advocate this approach, arguing that the use of longer-term averages (instead of characteristics that vary over time and cross section) significantly improves the reliability of $\mathrm{DiD}$ estimates.

Our coefficient of interest is $\alpha_{0}$. In the case of the lending growth regression, we wish to identify $\alpha_{0}=\beta_{0}$ whereas in the GDP growth regression, we wish to obtain $\alpha_{0}=\gamma \times \beta_{0}$. In our discussion here, we focus on the GDP growth regression but everything is analogous for lending growth. To see how our approach achieves identification of our parameters $\gamma$ and $\beta_{0}$, note first that the within-prefecure time-series correlation between local lending supply and local shocks that caused the bias in equation (3) is much reduced by our use of a countrywide shock-variable: we can estimate $\alpha_{0}$ and $\alpha_{1}$ by OLS whenever $\operatorname{cov}\left(\operatorname{SHOCK}_{t}, \nu_{t}^{k}\right)=0$, conditional on the controls $X^{k} \times$ SHOCK$_{t}$ and $Z_{t}^{k}$. Any remaining correlation of $\mathrm{SHOCK}_{t}$ with $v_{t}^{k}$ such that $v_{t}^{k}=\delta$ SHOCK $_{t}+\epsilon_{t}^{k}$ will be absorbed by time effects in our estimation.

A more serious challenge to identification could arise if the correlation between $\mathrm{SHOCK}_{t}$ and the uncontrolled factors $\nu_{t}^{k}$ varied in the cross-section as a function of SME and FI. Suppose that $v_{t}^{k}=\delta^{k} \times \mathrm{SHOCK}_{t}+\epsilon_{t}^{k}$ where $\delta^{k}=\delta_{S M E} \times \mathrm{SME}^{k}+\delta_{F I} \times \mathrm{FI}^{k}$. For the GDP growth 
regression, we would then obtain

$$
\Delta \mathrm{GDP}_{t}^{k}=\left[\gamma \times \beta_{0} \times \mathrm{SME}^{k} \times \mathrm{FI}^{k}+\left(\gamma \times \beta_{1}+\delta_{F I}\right) \times \mathrm{FI}^{k}+\delta_{S M E} \times \mathrm{SME}^{k}\right] \times \mathrm{SHOCK}_{t}+\epsilon_{t}^{k}
$$

Even in this case, OLS would still give us an unbiased estimate of $\alpha_{0}=\gamma \times \beta_{0}$, even though there would now be a bias in the estimate of the average size of the interaction between firm borrowing and bank lending channel, $\alpha_{1}=\gamma \times \beta_{1}+\delta_{F I}$. Hence neither $\mathrm{SME}^{k}$ nor $\mathrm{FI}^{k}$ has to be cross-sectionally uncorrelated with $v_{t}^{k}$ for our identification of $\alpha_{0}=\gamma \times \beta$ to be valid. The OLS estimate of $\alpha_{0}$ will be unbiased as long as the conditional correlation

$$
\operatorname{cov}\left(\mathrm{SME}^{k} \times \mathrm{FI}^{k}, \delta^{k} \mid \mathrm{FI}, \mathrm{SME}^{k}, \text { controls }\right)=0
$$

which is the assumption necessary for exact identification of the OLS regressions that we present in this paper.

This assumption is still likely not to be entirely satisfied in the data but we build on Khwaja and Mian (2008) in arguing that the correlation $\operatorname{cov}\left(\mathrm{SME}^{k} \times \mathrm{FI}^{k}, \delta^{k}\right)<0$. Since theory implies that $\gamma \times \beta_{0}>0$, this biases the estimate of $\alpha_{0}$ downwards. This would mean that the OLS estimate is conservative and therefore informative. Similar to Khwaja and Mian (2008) our argument rests on the cross-prefectural heterogeneity in the structure of bank-firm relationships that is suggested by our theory. Specifically, the credit reallocation channel implies that in high-SME / high-FI prefectures, the typical customer of an integrated bank is much more likely to be an SME and that SMEs are more likely to bank with integrated rather than local banks. Below, we provide empirical evidence that this indeed the case. Hence, in the high-SME/high-FI prefectures, the firms most vulnerable to local shocks (SMEs) were relying on the type of banks (integrated banks) that were the most exposed to the bank liquidity shock. This suggests that $\operatorname{cov}\left(\mathrm{SME}^{k} \times \mathrm{FI}^{k}, \delta^{k}\right)$ is indeed negative.

However, we do not have micro data that would allow us to directly check this correlation at the firm-bank-level. We overcome this limitations by using an instrument for $\mathrm{FI}^{k}$ 
using a variable that will be provided to us by our discussion of the historical origins of the regional segmentation of Japan's banking market below- the number of silk reeling filatures (per capita) in a prefecture in the late 19th century. In this case, our identifying assumption becomes

$$
\operatorname{cov}\left(\mathrm{SME}^{k} \times \mathrm{SILK}^{k}, \delta^{k} \mid \mathrm{FI}, \mathrm{SME}^{k}, \text { controls }\right)=0 .
$$

We then show that the OLS-estimate is indeed lower than the IV estimate, consistent with $\operatorname{cov}\left(\mathrm{SME}^{k} \times \mathrm{FI}^{k}, \delta^{k}\right)<0$ and thus with the theoretical mechanism.

\subsection{Regional segmentation in Japan's banking market}

The regional tiering of Japan's bankings system is well documented in the literature (Hoshi and Kashyap (2004); Kano and Tsutsui (2003)) and provides us with a natural indicator of cross-prefectural differences in banking integration (our measure $\mathrm{FI}^{k}$ ) : the prefecture-level share in bank lending accounted for by banks that operate nationwide or at least in many prefectures (and that therefore can pool bank funds across prefectures) vs. those that operate only in one prefecture. We refer to such banks as 'integrated' and to all those operating in only one prefecture as 'local'. For each type of bank (integrated and local ) we construct pre-1990 averages of prefecture-level lending shares from data on bank lending by prefecture and by bank type from the Bank of Japan (BoJ).

The group of integrated banks comprises Japan's biggest banks, the so-called 'mega' or 'city' banks, all of which operate nationwide. It also includes large, regional banks (so-called first-tier regional banks) that have outgrown their local origins and operate nationwide or at least in a larger number of prefectures. The prefecture-level BoJ data to which we have access does not allow us to distinguish between lending by mega banks and first-tier regional banks, but from our perspective it is useful anyway to consider both banks as integrated banks. Due to their larger geographic presence, first-tier regional banks can meaningfully operate internal capital markets between prefectures, which makes them more like mega banks and 
distinguishes them from purely local (second-tier regional) banks. Also, the business model of first-tier banks is characterized much more clearly by arm's-length lending, whereas the purely local banks we will focus on tend to be cooperatives or mutuals and largely engage in relationship lending to their SME members.

Local banks in Japan fall into two main groups: mutual banks (Sogo banks, also often referred to as second-tier regional banks) and industrial credit associations (Shinkins). By their statutes, these banks are mostly organized as cooperatives that, from the outset, were set up to provide finance to local small businesses in the manufacturing sector. Client SMEs usually also are members of these associations or cooperatives and many local banks, in particular the Shinkin, have explicit size caps (in terms of revenue or employment) on the membership firms. They also have designated, statutory areas of operation, making them genuinely local banks. These features of Japan's local banks have several interesting implications for our analysis: first, the ties between local banks and their small-business customers are particularly tight in the Japanese context. Secondly, it helps the interpretation of our results and our identification that local banks are de facto excluded from lending to non-SME (big) firms. Hence, while big firms can borrow only from the big, integrated banks (and, if very big, from the bond-market), SMEs can borrow from local banks and, in principle, also from integrated banks.

Endogeneity of regional banking integration Conditioning on the level of regional financial integration observed at the beginning of the lost decade could bias our empirical results, e.g. because integrated banks might have allocated credit to areas with relatively higher growth expectations already in the 1980s, leading us to find relatively more positive growth experiences in these areas after 1990. To alleviate such endogeneity concerns, we propose to use a historical instrument for regional banking integration in 1990. Specifically, we build on our work in Hoffmann and Okubo (2021) who provide detailed historical evidence that cross-regional differences in the importance of regional vs. nationwide banks ultimately re- 
flect long-standing differences in the particular model of local financial development. These differences can be traced back in history to the opening of Japan for international trade after 1854. Specifically, when silk reeling emerged as Japan's first main export industry in the late 19th century, it fostered the development of a specific model of export finance that was centered on small, local cooperative banks. Hoffmann and Okubo (2021) discuss how the local segmentation of credit markets implied by this particular cooperative model of banking persisted for over a century. We refer to this persistence as the 'silken thread' and document it in Figure 2, which plots the (logarithmic) number of silk filatures per head of population in a prefecture in 1895 against integrated banks' average prefecture-level lending share between 1980 and 1990. There is a clear negative relation between integrated banks' lending share and the number of silk filatures-to the present day, the former silk regions have a relatively low degree of financial integration with the rest of the country.

Table 2, adapted from Hoffmann and Okubo (2021), further illustrates the relevance of silk as an instrument for regional banking integration. The coefficient of a cross-sectional regression of pre-1990 lending shares on silk filatures is significant for both bank types-negative for integrated banks, positive for the share of local banks. ${ }^{8}$ We also run the same regression with a set of controls: the pre-1990 relative GDP of a prefecture, a dummy for the core prefectures and the (logarithmic) distance to Yokohama, as the first and biggest open port. The link between the importance of silk reeling and lending shares remains unaffected by these controls, and the individual t-statistics in the regressions with controls are all greater than four in absolute value. The number of filatures therefore clearly seems relevant as an instrument for financial integration.

We discuss the exclusion restriction next. We acknowledge that silk may be correlated with post-1990 prefecture-level outcomes in other ways than just via its impact on banking integration. This might be true in particular with respect to the impact of silk on the de-

\footnotetext{
${ }^{8}$ Note that the share of integrated banks is not unity minus the share of local banks in our data because there are some smaller agricultural cooperative banks as well as some public banks which account for a certain share of lending in most prefectures.
} 
velopment of the manufacturing sector and on industrial structure more generally. While we will control for these factors in our regressions, we note that the identifying assumption for our coefficient of interest is not that that $\operatorname{cov}\left(\mathrm{SILK}^{k}, \delta^{k}\right)=0$ but rather that $\operatorname{cov}\left(\mathrm{SME}^{k} \times\right.$ $\left.\mathrm{SILK}^{k}, \delta^{k}\right)=0$. Hence, the exclusion restriction amounts to assuming that silk affects the regional transmission of the crisis via banking integration only given the prefecture's SMEshare. $^{9}$

\section{Data}

We use data from 46 Japanese prefectures (excluding Okinawa). Nominal prefectural GDPs and population data are taken from the Annual Report on Prefectural Accounts (Cabinet Office of Japan). We deflate using the countrywide consumer price index, obtained from the Ministry of Internal Affairs and Communications. The importance of small manufacturing firms in terms of employees and value added at the prefectural level is taken from the Census of Manufacturers in Japan by the Ministry of Economy, Trade and Industry. We define SMEs as having fewer than 300 employees. ${ }^{10}$ The lending data by bank type (city and first-tier regional banks, Sogo banks, Shinkin, Shoko Chukin, etc.) at the prefecture level are taken from the Economic Statistics Annual by Prefecture (Bank of Japan). The prefecture-level breakdown of these data by bank type only runs to 1996. GDP and SME data cover the period 1980-2005.

Prefectural borders in Japan have remained largely unchanged since the early 1890s. This allows us to use late 19th-century prefecture-level data as instrument for banking integration in the 1980s. Data on the number of silk filatures in 1895 are taken from Zenkoku Seishi Kojo Chosa (Survey of Silk-reeling Factories throughout Japan). Prefecture-level data on population

\footnotetext{
${ }^{9}$ This, in particular, allows for the possibility that the development of the silk industry affected the emergence of a manufacturing sector with many SMEs, a point we explore in more detail in Hoffmann and Okubo (2021). We are grateful to Tarek Hassan for pointing out this important issue. In spite of the generality of this assumption, there could still be a concern that the silk industry affected financial sector development more generally, thus leading to better access to finance for SMEs irrespective of the degree of banking integration. However, Hoffmann and Okubo (2021) show that silk reeling mainly affects the local segmentation of banking markets, not their general level of development.

${ }^{10}$ This cutoff corresponds to the maximum number of employess that SMEs are allowed to have to remain eligible as members and customers of mutual and industrial cooperative (Shinkin) banks.
} 
in 1895 are from the Nihon Teikoku Minseki Kokouhyo (Registered Household Tables of Imperial Japan).

Table 1 provides a first look at the data. For each prefecture, the first two columns of the table present averages over the period 1980-1990 of integrated banks' lending shares and of our measure of SME importance (by valued added). The last two columns report post-1990 (1991-2005) prefectural GDP growth rates and the growth rates of lending by integrated banks (1991-96 averages). The table highlights the core economic areas that we define to include Greater Tokyo (Tokyo, Chiba, Saitama and Kanagawa-with Yokohama as the major city), the Kansai region (Osaka, Hyogo-with Kobe as the major city—and Kyoto) and Aichi prefecture (with Nagoya as the major city). The cross-prefectural standard deviations show that for each of these characteristics, there is considerable variation around the mean. The average lending share of city banks is around 55 percent, ranging from just over 40 percentto over 70 or even 80 percent in Greater Tokyo and other core prefectures. The GDP share of small manufacturing firms is around 16 percent, ranging from around 10 percent to almost 25 percent. A visual impression of the regional distribution of pre-1990 characteristics (SME importance and banking integration) and post-1990 GDP and lending growth can be gleaned from the two maps in Figure 3.

\section{The Reallocation Channel in Bank Lending}

\subsection{Baseline results}

In this section, we document the credit reallocation channel in prefecture-level bank-lending data. Table 3 reports the results for our reduced-form specification (5) where lending growth is the dependent variable. The first column is for aggregate lending growth in the prefecture. The second and third columns break lending down by bank type, with column (2) reporting results for lending growth of integrated (i.e. City) bank and column (3) for local banks. The estimates strongly support the predictions of our stylized model: the coefficient on the triple 
interaction term SME $\times$ FI $\times$ SHOCK is positive and significant for prefecture-aggregate lending (column (1)). This pattern is indeed driven by the integrated City banks (see column (2)) which are able to reallocate credit across prefectures. Conversely, the coefficient is small and insignificant for the local banks which do not have this option (column (3)). Note that we also find a negative and significant coefficient $\beta_{1}$ on the interaction $\mathrm{FI}^{k} \times \mathrm{SHOCK}_{t}$. Consistent with the earlier literature (Imai and Takarabe (2011)), this shows that—given that the bank liquidity shock primarily affected integrated banks—the bank lending channel impacted prefectures more strongly if they were more integrated.

As discussed in the theory section, our theoretical framework allows us to further strengthen this interpretation of Japan's bursting bubble as a negative credit supply shock. To see this, consider as plausible alternative a negative shock to the credit demand of firms. Such a shock would lead financially integrated banks to withdraw funding more strongly from the highSME prefectures, leading the coefficient on SME $\times$ FI $\times$ SHOCK to become negative. This would be because an initially equal drop of credit demand by big firms and SMEs would, on impact, lower the local interest rate more in the high-SME region, giving integrated banks an incentive to reallocate credit away from these regions in an attempt to maximize profits by equalizing interest rates across prefectures. Hence, the positive sign on the triple interaction (coupled with the negative sign on $\mathrm{FI}^{k} \times \mathrm{SHOCK}_{t}$ ) clearly suggests that Japan's lost decade was caused by a negative liquidity shock to the integrated banks.

We acknowlegde, however, that the bursting of Japan's country-wide land price bubble is likely to have had pervasive effects on both both credit demand and supply and that our theory can only help us in identifying the predominant nature of the common, country-wide component of the shock. Therefore, in order to minimize the impact of confounding factors further, the specifications in Table 3 and in the remainder of the paper, also include a rich set of controls with which we account for local differences in the impact of the shock on local economic conditions and on local credit demand in particular:

i) To account for the impact of cross-regional differences in industrial structure, we con- 
struct a measure of predicted prefecture-level output growth as the weighted average of countrywide sector-level growth rates. As weights we use the pre-1990 averages of sector shares for each pefecture. Clearly, predicted (i.e. expected) output growth would also be an important driver of local credit demand.

ii) Local land prices are an important indicator of the local stance of aggregate demand. Equally, they are an important driver of local credit demand since land is an important source of collateral for firms in Japan. We therefore control for local real estate shocks by including prefecture-level land-price growth.

iii) SMEs with their focus on local markets are likely to predominantly post local land as collateral (Gan (2007); Shimizu (1992)). Hence we expect the price of local land to have a particular important role on local credit demand in high-SME prefectures. This is why we also include an interaction between the SME share and local land price growth.

iv) The interaction SME $\times$ SHOCK$_{t}$ is also present in all our specifications. Clearly, this must be the case simply to make sure that the higher-order interactions $\operatorname{SME} \times$ FI $\times$ SHOCK which are our main interest here do not appear spuriously significant. But we note that $\mathrm{SME} \times \mathrm{SHOCK}_{t}$ also helps control for the potentially heterogeneous impact of the aggregate shock on the output and thus credit demand of local SMEs.

iv) While the burst of the bubble mainly hit the larger integrated banks, regional banks were also likely to be affected. We therefore allow for heterogeneity in local banks' exposure to the aggregate shock. We do this by including an interaction between SHOCK $_{t}$ and the pre-1990 average real estate lending exposure (as a fraction of total lending) of second-tier regional banks in the prefecture. Data on these exposures are obtained from the Nikkei NEEDS data base.

v) We control for geographic remoteness by including an interaction between the aggregate shock and a prefecture's distance to biggest and (historically first open) port, Yokohama.

vi) Finally, we allow the impact of the aggregate shock to differ between the core and more peripheral prefectures. 
Instrumental variable estimates As discussed above, the extent to which a prefecture's banking market was integrated with the rest of the country at the onset of the crisis could be endogenous with respect to local economic conditions. In Table 4, we therefore present estimates of our baseline regression in which FI is instrumented with the number of silk filatures per head of population in 1895. Again, the first column reports results for prefecture-level aggregate lending, while the other columns distinguish between lending by integrated and local banks. The IV results confirm the pattern already apparent from the previous OLS estimates in Table 3: the reallocation term $\mathrm{SME}^{k} \times \mathrm{FI}^{k} \times \mathrm{SHOCK}_{t}$ is significant and positive for the integrated banks only. The bank-lending term $\mathrm{FI}^{k} \times \mathrm{SHOCK}_{t}$ is generally significantly negative.

Comparing the IV and OLS estimate sheds light on the cross-prefectural heterogeneity in bank-firm relationships and allows us to check whether it is consistent with our theoretical mechanism. Note that the the IV estimates in Table 4 are all bigger than the corresponding OLS estimates in Table 3. Based on our earlier discussion, this implies that the reallocation term $\mathrm{SME}^{k} \mathrm{FI}^{k}$ and the prefecture-specific loadings $\delta^{k}$ on any unmodelled demand effects from the aggregate land price decline are negatively correlated in the cross-section, $\operatorname{cov}_{K}\left(\mathrm{SME}^{k} \mathrm{FI}^{k}, \delta^{k}\right)<0$. As we document in the memorandum items at the bottom of Table 4, SMEs in high-SME/ high-FI prefectures are more likely to have an integrated bank as their main bank and in these prefectures a larger share of integrated banks' customers are SMEs. ${ }^{11}$ Small firms are less likely than big firms to export and thus serve mainly local markets. They will therefore likely have experienced larger declines in demand for their output (and thus to have demanded less credit) following the aggregate shock. At the same time, the bank liquidity shock faced by integrated banks was generally higher than that faced by the average local bank. Hence, in the high-SME/ high-FI prefectures the firms that were most exposed to the negative local demand effects of the downturn (SMEs) were particularly likely to be linked to

\footnotetext{
${ }^{11}$ First, we obtain a prefecture-level measure of the share of SMEs reporting a city bank as their main bank relationship from the 2002 edition of the survey of enterprise finance (SEF). Regression I in the memorandum item shows that this measure is highly correlated with $\mathrm{FI}^{k}$. Then Using data from the 2006 edition of the TSR data base, we compute the share of SME in the customer base of city banks. This share is highly correlated with $\mathrm{SME}^{k}$ (regression II).
} 
integrated banks who had the highest balance sheet exposure to the land price decline. It is therefore plausible that the negative fallout from this shock on credit demand in high-SME/ high-FI prefectures was particularly strong, so that $\operatorname{cov}_{K}\left(\mathrm{SME}^{k} \mathrm{FI}^{k}, \delta^{k}\right)<0$.

Table 5 provides evidence on the fit of the first-stage of our IV regressions. While our results in Table 2 demonstrated the relevance of silk as an instrument for regional banking integration in the cross-section, here we explore how well our instruments work in identifying the role of banking integration in our baseline panel setting with its multiple interaction terms. The endogenous variable, FI, appears twice as an interaction in our regressions: in the bank lending term, $\mathrm{FI}^{k} \times \mathrm{SHOCK}_{t}$, and in the reallocation term $\mathrm{SME}^{k} \times \mathrm{FI}^{k} \times \mathrm{SHOCK}_{t}$. We therefore need two instruments and we use our silk variable interacted with $\mathrm{SHOCK}_{t}$ and SMESHOCK $_{t}$ for this purpose. Our instruments are relevant for both endogenous variables. At the bottom of the table, we report simple first-stage $F$-statistics for the regression of the interaction term of the post-1990 dummy with $S M E \times F I$ on the instruments. The value of this first-stage $F$-statistic is above 10 throughout, which provides a first indication as to the strength of the instruments with respect to the individual endogenous regressors (Staiger and Stock (1997)). However, first-stage $F$-statistics can be misleading with respect to the overall instrument strength since the benchmark critical values in the literature are not generally valid if the errors are heteroskedastic. Furthermore, high conventional first-stage F-statistiscs can be insufficient for identification if there is more than one endogenous variable, as is the case here. We therefore also report the Kleibergen and Paap (2006) rank (KP-rk) statistics for underidentification which tests the null that the matrix of regression coefficients of the two endogenous variables on the two instruments has a rank defect. We report KP-rk for both robust (HAC) and clustered standard errors. In both cases we strongly reject the null. Finally, we also report the conditional $F$-statistics recently suggested by Sanderson and Windmeijer (2016). Differently from the traditional Cragg and Donald (1993) and the Kleibergen-Paap Kleibergen and Paap (2006) rank tests for underidentification the conditional F-statistics also allows us to assess if and to which extent the individual endogenous variables are poten- 
tially weakly identified. Again, we report the conditional statistics with robust and clustered standard errors and bootstrap their p-values using the procedure provided in the R package ' $I f e^{\prime}$ (Gaure $\left.(2019,2013)\right)$. The tests suggest that both variables-and the reallocation term in particular-are robustly identified.

Local interest rate differentials In the simple model in Figure 1, the reallocation channel reflects integrated banks' attempt to maximize profits by arbitraging interest rate differentials between prefectures. When faced with an adverse liquidity shock, regional banks would charge their SME customers higher interest rates than integrated banks facing a similar shock. This happens because the latter can optimally reallocate lending towards the high-SME prefecture, thus arbitraging interest rate differentials (reflecting differences in the elasticity of credit demand) between prefectures.

While we have no direct observations on prefecture-level differences in interest rates charged by the integrated banks, we can obtain information about the average interest rates charged by local banks from their balance sheets. ${ }^{12}$ In prefectures, where integrated banks have strong links with SME customers we would expect that local banks would have limited ability to charge their own SME customers higher rates following a shock to their balance sheets. In such prefectures, credit reallocation by integrated banks should keep interest rates in line with the rest of the country. Conversely, in prefectures where integrated banks have a weak position in SME-finance, the local banks should have more leeway to increase their rates.

This is what our results in Table 6 bear out. We split the sample into two groups of prefectures , depending on the market power of integrated banks in local SME lending markets. ${ }^{13}$

\footnotetext{
${ }^{12}$ Following Kano and Tsutsui (2003), we construct the average interest rate charged by local banks as interest income divided by total lending of Tier 2 (Sogo) banks contained in the Nikkei NEEDS database. These banks largely coincide with the notion of local banks in our prefecture aggregates. As an indicator of the size of the shock to local banks, we have already used local bank's exposure to the local real estate market as a control in our previous regressions.

${ }^{13}$ As our measure of the market power of integrated banks we use data from the survey of enterprise finance (SEF) that allows us to measure the share of local SMEs that report an integrated bank as their main bank relationship.
} 
For both groups, Table 6 reports regressions of local banks' interest rates on measure of the shock to local banks' balance sheets, the interaction between local banks' real estate exposure and the the aggregate land price decline. As would be suggested by our theory, conditional on the shock to their balance sheets, local banks do not charge significantly higher interest rates in prefectures where integrated banks have a strong presence in SME lending. In these prefectures, the reallocation effect is likely to dominate the determination of interest rates and prefecture-specific credit supply shocks have no bearing on interest rates. Conversely, in prefectures where integrated banks have weak ties to SMEs,we estimate a much bigger positive and significant coefficient.

\subsection{How important is the reallocation channel?}

Our previous results establish the statistical significance of the reallocation channel. But how important is the channel quantitatively? We address this question by examining, for each prefecture $k$, the average annual post-1990 growth rate of integrated banks' lending that would be implied by our estimates of the reallocation and the bank lending channels respectively. Specifically, we measure the importance of the reallocation channel in prefecture $k$ by

$$
\operatorname{RA}_{9196}^{k}=\left(\prod_{t=1991}^{1996} \exp \left(-\widehat{\beta}_{0} \times \mathrm{SME}^{k} \times \mathrm{FI}^{k} \times \text { LANDPRICEGROWTH in CORE } t\right)\right)^{1 / 6}-1
$$

where $\widehat{\beta}_{0}=3.27$ is our estimate of the coefficient on the reallocation term from Table 3 , column (2). Quite analogously, we measure the the bank lending channel by

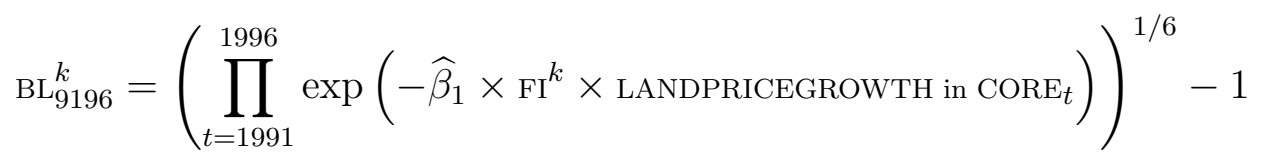

where $\widehat{\beta}_{1}=-0.60$ is the corresponding coefficient on the bank lending term from the same regression. We plot $\mathrm{RA}_{9096}^{k}$ and $\mathrm{BL}_{9096}^{k}$ as bar charts in Figure 4. The prefectures are in the official geographical order from Hokkaido in the north-east to Kagoshima in the south-west. 
For each prefecture, we also plot the net predicted flows implied by adding up the two channels. The first feature that is visually apparent from the graph is that the reallocation channel is of the same order of magnitude as the bank lending channel. For the median prefecture it accounts for an average annual increase of lending of 4.25 percent over the 1990-96 period. Conversely, the bank lending channel accounts for an annual decline of 5.3 percent for the median prefecture. Hence, both effects are quanitatively of the same order of magnitude. However, while the bank lending channel has obtained considerably attention in the literature, the role of geographical reallocation of credit during a major financial crisis has never been formally investigated.

The figure also bears out that the reallocation channel is not driven by a retrenchment of lending from peripheral areas to the big centers. In fact, some of the main beneficiaries of credit reallocation are relatively remote but highly industrialized prefectures such as Fukushima, Ibaraki or Gunma in the northeast or prefectures in central Japan such as Yamanashi, Nagano or Gifu with their high share of SMEs and strong manufacturing bases. Conversely, the negative effect of the bank lending channel is particularly relevant in the highly financially integrated big cities , notably in the greater Tokyo area, which is consistent with the literature (Imai and Takarabe (2011)).

While Figure 4 shows us the absolute orders of magnitude of lending implied by the two channels, it is also informative to zoom in on the relative net flows of credit across prefectures that are implied by our estimates. To this end, in Figure 5, we remove the cross-sectional mean from our estimates of the reallocation and the bank lending channels respectively and reorder prefectures in the order of the net effect of the two channels. The figure therefore provides us with an impression of the geographical redistribution of credit after 1990 and how each of the two channels contributed to it.

The implied geographical redistribution of credit is sizable, ranging from around -2 percent relative annual credit growth (if we exclude Tokyo) to +2 percent. ${ }^{14}$ This implies that over

\footnotetext{
${ }^{14}$ We identify the strongest negative net flows for Tokyo prefecture with about -3 percent annual credit growth (relative to the country-wide average) in the post-1990 period. Given the high level of financial integra-
} 
the 1990-96 period, cumulative credit growth in the prefectures that benefited most from the geographical redistribution, credit was about 25 percent higher (relative to the country-wide mean) in 1996 than in 1990. Importantly, the reallocation channel plays a key role in driving this redistribution: it is visually apparent from Figure 5 that negative net flows occur predominantly because the reallocation channel is negative. Conversely, positive net flows, to the right of the graph, are also predominantly associated with a high positive contribution of the reallocation channel. A similar pattern is not detectable for the bank lending channel. ${ }^{15}$

\section{The real effects of credit reallocation}

In this section, we investigate the role of credit reallocation for regional output growth and business cycle synchronization.

Effects on GDP growth during the lost decade In Table 7, we run our baseline reduced form regression (5), but now with prefecture-level GDP growth as the dependent variable. Column (1) reports results for OLS, column (2) the two-stage estimation using silk as instrument. As for our previous specifications, we find the coefficient on the reallocation term $\mathrm{SME}^{k} \times \mathrm{FI}^{k} \times \mathrm{SHOCK}_{t}$ is significantly positive in both regressions. Also, the IV estimate is again higher, consistent with our earlier findings that the most affected firms (SMEs) are matched to the most affectected type of banks (i.e. the integrated banks) in prefectures were $\mathrm{SME}^{k} \times \mathrm{FI}^{k}$ is high. Hence, the reduced form regressions with output growth as dependent variable are consistent with our conjecture that the reallocation of lending helped stabilize output in prefectures with many SMEs.

tion of Tokyo prefecture and the relatively small share of SMEs in the capital's economy, the negative effect of the bank lending channel, maybe unsurprisingly, dominates the net effect. It is, however, apparent that high net outflows are not a universal feature fo the big cities. For example, while Osaka is highly financially integrated, but it has a much higher share of SMEs in its local economy, so that the effects of the reallocation and the bank lending channels roughly cancel out. Accordingly, Osaka finds itself virtually in the middle of the distribution of the net effects.

${ }^{15}$ This visual impression is corroborated by a rank correlation of 0.54 between the reallocation channel and the net flow. Conversely, the rank correlation between the bank lending channel and the net flow is only 0.14. 
To get an impression of how the reallocation effect stabilized output in credit-dependent high-SME prefectures over time, we run the following regression

$$
\Delta \mathrm{GDP}_{t}^{k}=\eta_{t} \times \mathrm{SME}^{k} \times \mathrm{YEAR}_{t}+\mathrm{YEAR}_{t}+\mathrm{PREF}^{k}
$$

where $\mathrm{YEAR}_{t}$ and $\mathrm{PREF}^{k}$ denote time effects and prefecture dummies respectively. ${ }^{16}$ The sequence of coefficients $\left\{\eta_{t}\right\}_{t=1980 \ldots 1996}$ gives us the time-varying impact of the SME share on GDP growth. If credit reallocation stabilized GDP during the lost decade, it should be the case that the link between SME and GDP growth in prefectures with high levels of banking integration $\mathrm{FI}^{k}$ should remain stable relative to the pre-shock period. Conversely we would expect a given level of $S M E$ to be associated with lower GDP growth in prefectures that are less financially integrated. To verify this conjecture, we split our sample into two subsamples of high/low FI prefectures and run regression (11) on each of those. To make the implied GDP growth rates comparable, for each sub-sample we multiply the estimates $\left\{\eta_{t}\right\}_{t=1980 \ldots 1996}$ with the median SME share of all prefectures. The product $\eta_{t} \times \mathrm{SME}^{\text {median }}$ then gives us the predicted GDP growth (relative to the country-wide mean) for a prefecture with an average SME share, depending on whether the prefecture had high or low levels of banking integration.

Figure 6 plots the results. High-FI prefectures, saw much more stable GDP growth (compared to the pre-crisis period) than low-FI prefectures. Note also that both groups have essentially parallel pre-shock trends in GDP growth. Both groups also experience a sharp initial decline in GDP following the burst of the landprice bubble. However, recovery in the highFI prefectures is very swift. This contrasts with the low-FI prefectures where the slump is much more protracted and which only reach their pre-1990 levels of GDP growth after the middle of the lost decade again.

\footnotetext{
${ }^{16}$ Written here as a panel-regression, this regression can also be interpreted as a sequence of cross-sectional regressions of GDP growth on the pre-1990 prefecture-level SME shares.
} 
Impact on business cycle synchronization We ask next to what extent credit reallocation helped limit the asymmetry of regional business cycles in Japan after the burst of the real estate bubble. We follow (Morgan et al., 2004) and Kalemli-Ozcan et al. (2013a,b) and construct a time-varying measure of business cycle synchronization as follows. For each prefecture, we regress GDP growth on a common, country-wide component $\mathrm{COUNTRY}_{t}$ and a prefecture dummy:

$$
\Delta \operatorname{GDP}_{t}^{k}=\operatorname{COUNTRY}_{t}+\mathrm{PREF}^{k}+v_{t}^{k}
$$

The residual of this regression, $v_{t}^{k}$, is the idiosyncratic component of GDP growth in prefecture $k$ and year $t$. We construct two versions of $v_{t}^{k}$, one in which COUNTRY $t=\mathrm{YEAR}_{t}$ is a year-fixed effect and on which COUNTRY $_{t}$ is the sum of a constant and crisis dummy that is unity after 1991 and zero before. Whereas the first version captures idiosyncratic movements as year-to-year deviations from the counry-wide growth rate of GDP, the second defines them as deviations from the longer-term (post-1991) average country-wide growth rate. For both versions, the synchronization of prefecture $k$ with the rest of the country can then be measured by

$$
\operatorname{SYNC}(i)_{t}^{k}=-\left|v_{t}^{k}\right|
$$

where $i=1$ stands for the version where COUNTRY ${ }_{t}$ is a year-effect and $i=2$ for the longerterm version where COUNTRY is captured by a dummy. We regress the two synchronization measures $\operatorname{SYNC}(i)_{t}^{k}$ on our by now "usual" right hand side as specified in our baseline specification. Results are in Table 8. In both specifications, the coefficient on the reallocation term is significant and positive, whereas the stand-alone banking integration term $\mathrm{FI}^{k} \times$ SHOCK$_{t}$ is insignificant.

Consistent with (Morgan et al., 2004) and Kalemli-Ozcan et al. (2013a,b), these findings confirm the theoretical prediction that a major credit supply shock increases synchronization. Kalemli-Ozcan et al. (2013a,b) show that financial integration is associated with higher business cycle synchronization during financial crises, when common credit supply shocks 
dominate in the data. This positive link between financial integration and synchronization during a crisis could have two different sources that the earlier literature has not attempted to disentangle. First, financial integration could increases the exposure to shocks hitting common lenders (i.e. through the bank lending channel). Secondly, financial integration could help risk sharing by facilitating credit reallocation, thus eliminating the potentially heterogeneous real effects of a common credit supply shock. Our results here suggest that-at least in a highly integrated country like Japan - it is predominantly the profit-maximizing reallocation of credit by banks that explains why output synchronization increases during the crisis.

Credit reallocation and the firm-borrowing channel We conclude by examining how taking account of credit reallocation affects estimates of the coefficient $\gamma$ in the structural firm-borrowing equation (3). We can interpret $\gamma$ as a simple measure of how a elastic firms' output is to a shortfall in funding. If reallocation towards the least elastic borrowers helps share risk across regions, we could expect a given decline in funding to be associated with a lower pass-through of lending shocks to real output.

Table 9 presents estimates of three specifications of the firm-borrowing equation (3). In the first, as in Imai and Takarabe (2011), we instrument lending using the fitted value from a regression of lending growth on $\mathrm{FI} \times \mathrm{SHOCK}_{t}$ (and controls). This specification therefore only considers the bank lending channel. In the second and third specifications, we consider the reallocation and bank lending channels jointly by using the fitted values from the OLS and IV regressions for integrated banks' lending growth as instruments, respectively. ${ }^{17}$

The results in Table 9 show that taking account of both channels jointly substantially lowers the estimate of $\gamma$. Accounting only for the bank-lending channel, we find that $\gamma=$ 0.5, consistent with the estimate in Imai and Takarabe (2011). Once we also take account of the reallocation channel, the estimate of $\gamma$ drops to 0.4 or even 0.3 when using silk as the instrument.

\footnotetext{
${ }^{17}$ These correspond to column (2) of Table 3 and Table 4 respectively.
} 
Figure 7 illustrates how lower estimates of $\gamma$ also impact estimates of the regional heterogeneity in GDP responses to the crisis (and thus, effectively, of macroeconomic risk sharing). For each prefecture, the left panel plots post-1991 average GDP growth (relative to the country-wide mean) as implied by the estimates of the firm-borrowing equation in Table $9-$ once for the "bank-lending-channel-only" model in column (1) and once for the model with reallocation in column (3). The implied cross-regional heterogeneity in GDP growth rates is substantially lower for the model with reallocation. Furthermore, the right panel of Figure 7 shows that accounting for credit reallocation also matches actual prefectural GDP growth rates more closely than the model that only accounts for the bank-lending channel.

Robustness In the appendix we provide further robustness checks. First, in Tables A.1, A.2 and A.3 we show that our main results continue to go through once we drop the the core prefectures with the biggest cities from our sample. Second, we document that our results also survive in what Bertrand et al. (2004) have called a 'before-after' regression; i.e., a crosssectional regressions of average post-1991 growth rates in GDP and lending on pre-1991 averages of $\mathrm{SME}^{k} \times \mathrm{FI}^{k}, \mathrm{FI}^{k}$ and $\mathrm{SME}^{k}$ (Table A.4). Third, we illustrate that the results also hold with alternative measures of SME importance and regional banking integration (Table A.5).

\section{Discussion and Conclusion}

The possibility to reallocate credit to arbitrage regional differences in the demand for credit is one of the major benefits from banking integration. Using the Japanese lost decade as a natural experiment, this paper has shown that the geographical reallocation of credit by regionally integrated banks is a major force in limiting economic asymmetries between the regions of a monetary union. Our analysis has exploited the historical variation in the extent to which Japans' regional banking markets are segmented to propose an instrument for regional banking integration. Our results complement detailed firm-bank level analyses which usually do not focus on geographical heterogeneity and the aggregate outcomes. We also provide a com- 
plementary, intra-national, perspective to studies in international banking by studying how banking integration contributes to macroeconomic risk sharing at the sub-national level during a major crisis.

Our results suggest that credit reallocation happens in a way that is consistent with integrated banks operating internal capital markets in a profit-maximizing manner. Another mechanism through which the financial system might allocate funds to regions with high credit demand could be that integrated banks have better access than local banks to external capital markets (e.g. through wholesale funding) and that this would allow them to keep lending up. While our data are not granular enough to formally rule out this interpretation, there are a strong indications that this was not the case. First, the integrated banks were hit hardest by the burst of Japan's land price bubble and generally had to shrink their balance sheets more than local banks. This makes it unlikely that their ability to tap wholesale markets drives our results. Rather, among the general retrenchment in lending, they retrenched relatively less from the regions with the least elastic demand for credit. Secondly, most of the major integrated Japanese banks are headquartered in a couple of major cities, in particular the Greater Tokyo area. Hence, even if some of the lending to the prefectures with relatively high demand for credit was financed by integrated banks via additional wholesale borrowing, the considerable regional heterogeneity in integrated banks' lending growth after 1991 would still have required an internal reallocation of funds by the integrated banks (since wholesale funds or bonds would generally be raised at head-quarter level).

However, our results siggest an important complementary role of external capital (bond) market access of firms during Japan's lost decade. In our stylized model of Figure 1 reallocation happens because the most elastic borrowers (big firms) turn away as integrated banks reduce credit-reflecting our assumption that these big firms have access to other forms of finance. Indeed, as discussed by Hoshi (1995) and Hoshi and Kashyap (2004), following the credit crunch of the early 1990s, big Japanese corporates started to turn away from their main banks, starting to issue more bonds instead. Figure 8 illustrates this development us- 
ing aggregate data on bank lending and bond issuance. ${ }^{18}$ Our interpretation of this fact is that the increase in bond issuance was the reaction of the least bank-dependent, most elastic borrowers (big corporates) to the reduction in integrated banks' credit. This effectively reduced bank credit demand by corporates and allowed integrated banks to allocate relatively more funds towards regions with inelastic demand for bank credit. During a major crisis, the bank-dependent borrowers in these regions could therefore borrow relatively more. Credit reallocation therefore kept output more stable (and more homogenous across regions) than it would otherwise have been. Arguably, the reallocation of credit by integrated banks could not have fulfilled this stabilizing role without bigger firms having found cheaper ways to borrow by issuing bonds. Our results therefore illustrate an important complementarity between developed capital (bond) markets and regionally integrated banking markets. They therefore also inform current debates about the relative importance of capital market and banking integration e.g. in the context of the European Monetary Union.

\footnotetext{
${ }^{18}$ Japan had gradually started to liberalize its private bond market from the early 1980s. This explains why bond issuance increases from an overall quite low level after 1991. But the graph clearly suggests that private bond issuance in 1994 was higher than ever before. By contrast, data from the Bank of Japan suggest that equity issuance stayed essentially flat during the 1990s, which is consistent with the depressed stock market during that period.
} 
Asdrubali, Pierfederico, Bent E. Sørensen, and Oved Yosha, "Channels of Interstate Risk Sharing: United States 1963-1990," Quarterly Journal of Economics, 1996, 111 (4), 10811110.

\section{Baskaya, Yusuf Soner, Julian di Giovanni, Sebnem Kalemli-Ozcan, José-Luis Peydro,} and Mehmet Fatih Ulu, "Capital flows and the international credit channel," Journal of International Economics, 2017, 108, S15-S22. 39th Annual NBER International Seminar on Macroeconomics.

Berger, Allen N., Nathan H. Miller, Mitchell A. Petersen, Raghuram G. Rajan, and Jeremy C. Stein, "Does function follow organizational form? Evidence from the lending practices of large and small banks," Journal of Financial Economics, May 2005, 76 (2), 237269.

Bertrand, Marianne, Esther Duflo, and Sendhil Mullainathan, "How much should we trust Differences-in-Differences Estimates?," Quarterly Journal of Economics, 2004, 119 (1), 249-275.

Bord, Vitaly M., Victoria Ivashina, and Ryan D. Taliaferro, "Large Banks and Small Firm Lending," NBER Working Paper w25184, National Bureau of Economic Research October 2018. https://www.nber.org/papers/w25184.

Cetorelli, Nicola and Linda Goldberg, "Banking Globalization and Monetary Transmission," Journal of Finance, October 2012, 67 (5), 1811-1843.

_ and Linda S. Goldberg, "Liquidity management of U.S. global banks: Internal capital markets in the Great Recession," Journal of International Economics, 2012, 88 (2), 299-311.

Chava, Sudheer and Amiyatosh Purnanandam, "The effect of banking crisis on bankdependent borrowers," Journal of Financial Economics, 2011, 99 (1), 116-135.

Constâncio, Vítor, “Synergies between banking union and capital markets union,” 052017. Keynote speech by Vítor Constâncio, Vice-President of the ECB, at the joint conference of the European Commission and European Central Bank on European Financial Integration, Brussels, 19 May 2017 [Accessed: 202105 20].

Cortés, Kristle Romero and Philip E. Strahan, "Tracing out capital flows: How financially integrated banks respond to natural disasters," Journal of Financial Economics, July 2017, 125 (1), 182-199. 
Cragg, John G. and Stephen G. Donald, “Testing Identifiability and Specification in Instrumental Variable Models," Econometric Theory, April 1993, 9 (02), 222-240.

de Haas, Ralph and Iman van Lelyveld, "Internal capital markets and lending by multinational bank subsidiaries," Journal of Financial Intermediation, January 2010, 19 (1), 1-25.

Dell'Ariccia, Giovanni, Enrica Detragiache, and Raghuram Rajan, "The real effect of banking crises," Journal of Financial Intermediation, January 2008, 17 (1), 89-112.

Demyanyk, Yuliya, Charlotte Ostergaard, and Bent Sorensen, "US Banking Deregulation, Small Businesses, and Interstate Insurance of Personal Income," Journal of Finance, 2007, LXII, No. 6, 2763-2801.

Gan, Jie, "Collateral, debt capacity, and corporate investment: Evidence from a natural experiment," Journal of Financial Economics, September 2007, 85 (3), 709-734.

Gaure, Simen, "Ife: Linear group fixed effects," The R Journal, Dec 2013, 5 (2), 104-117. User documentation of the 'lfe' package.

_ , lfe: Linear Group Fixed Effects 2019. https://CRAN.R-project.org/package=lfe.

Giannetti, Mariassunta and Andrei Simonov, "On the Real Effects of Bank Bailouts: Micro Evidence from Japan," American Economic Journal: Macroeconomics, January 2013, 5 (1), $135-67$.

- and Luc Laeven, "The flight home effect: Evidence from the syndicated loan market during financial crises," Journal of Financial Economics, April 2012, 104 (1), 23-43.

- and Steven Ongena, "Financial Integration and Firm Performance: Evidence from Foreign Bank Entry in Emerging Markets*," Review of Finance, 11 2007, 13 (2), 181-223.

Gilje, Erik P., Elena Loutskina, and Philip E. Strahan, "Exporting Liquidity: Branch Banking and Financial Integration," The Journal of Finance, 2016, 71 (3), 1159-1184.

Haas, Ralph De and Neeltje Van Horen, "Running for the Exit? International Bank Lending During a Financial Crisis," The Review of Financial Studies, January 2013, 26 (1), 244-285.

Hoffmann, Mathias and Iryna Shcherbakova-Stewen, "Consumption Risk Sharing over the Business Cycle: The Role of Small Firms' Access to Credit Markets," The Review of Economics and Statistics, November 2011, 93 (4), 1403-1416. 
_ and Toshihiro Okubo, "Comparative advantage and pathways to financial development: Evidence from Japan's silk reeling industry," UZH Economics Working Paper 387, University of Zurich May 2021. https://doi.org/10.5167/uzh-203421.

_ , Egor Maslov, Bent E. Sørensen, and Iryna Stewen, "Channels of Risk Sharing in the Eurozone: What Can Banking and Capital Market Union Achieve?, IMF Economic Review, September 2019, 67 (3), 443-495.

Holmstrom, Bengt and Jean Tirole, "Financial Intermediation, Loanable Funds, and the Real Sector," The Quarterly Journal of Economics, 1997, 112 (3), pp. 663-691.

Hoshi, T. and A. Kashyap, "The Japanese Banking Crisis: Where Did it Come from and How Will it End?," NBER Macroeconomics Annual 1999, 2000, 14, 129-201.

_ and _ , "Japan's Economic and Financial Crisis: an Overview," Journal of Economic Perspectives, 2004, 18, 3-26.

Hoshi, Takeo, "Evolution of the Main Bank System in Japan," in Mitsuaki Okabe, ed., The Structure of the Japanese Economy, Studies in the Modern Japanese Economy, Macmillan Press Ltd., 1995, pp. 287-322.

Hosono, Kaoru, Daisuke Miyakawa, Taisuke Uchino, Makoto Hazama, Arito Ono, Hirofumi Uchida, and Iichiro. Uesugi, "Natural Disasters, Damage to Banks, and Firm Investment," International Economic Review, 2016, 57, 1335-1370.

Imai, M. and S. Takarabe, "Bank Integration and Transmission of Financial Shocks: Evidence from Japan," American Economic Journal: Macroeconomics, 2011, 3(1), 155-183.

Jonghe, Olivier De, Hans Dewachter, Klaas Mulier, Steven Ongena, and Glenn Schepens, "Some Borrowers Are More Equal than Others: Bank Funding Shocks and Credit Reallocation," Review of Finance, February 2020, 24 (1), 1-43.

Kalemli-Ozcan, Sebnem, Bent Sørensen, and Oved Yosha, "Risk Sharing and Industrial Specialization: Regional and International Evidence," American Economic Review, 2003, 93 (3), 903-18.

_ , Elias Papaioannou, and Fabrizio Perri, “Global banks and crisis transmission,” Journal of International Economics, March 2013, 89(2), 495-510.

_, , and José-Luis Peydró, "Financial Regulation, Financial Globalization, and the Synchronization of Economic Activity," The Journal of Finance, 2013, 68 (3), 1179-1228. 
Kano, Masaji and Yoshiro Tsutsui, "Geographical segmentation in Japanese bank loan markets," Regional Science and Urban Economics, 2003, 33 (2), 157 - 174.

Khwaja, Asim Ijaz and Atif Mian, "Tracing the Impact of Bank Liquidity Shocks: Evidence from an Emerging Market," American Economic Review, September 2008, 98 (4), 1413-42.

Kleibergen, Frank and Richard Paap, "Generalized reduced rank tests using the singular value decomposition," Journal of Econometrics, July 2006, 133 (1), 97-126.

Kroszner, Randall S., Luc Laeven, and Daniela Klingebiel, "Banking crises, financial dependence, and growth," Journal of Financial Economics, April 2007, 84 (1), 187-228.

Martinez, Joseba, Thomas Philippon, and Markus Sihvonen, "Does a Currency Union Need a Capital Market Union? Risk Sharing via Banks and Markets,” NBER Working Paper w26026, National Bureau of Economic Research July 2019.

Miwa, Y. and J. M Ramseyer, "Japanese Industrial Finance at the Close of the 19th Century: Trade Credit and Financial Intermediation," Explorations in Economic History, 2006, 43 (1), 94-118.

Morgan, Donald P., Bertrand Rime, and Philip E. Strahan, "Bank Integration and State Business Cycles," Quarterly Journal of Economics, 2004, 119 (4), 1555-85.

Nakabayashi, Masaki, "The Rise of the Modern Silk Reeling Industry and Financial Institutions: The Formation of the Institution of Providing Advances on Documentary Bills," Japanese Yearbook on Business History, 2001, 18, 119-139.

_ , "The Rise of a Factory Industry: Silk Reeling in Suwa District," in Masayuki Tanimoto, ed., The Role of Tradition in Japan's Industrialization, Vol. Volume 2 of Japanese Studies in Economic and Social History, Oxford University Press, 2006.

_ , "Imposed Efficiency of the Treaty Port: Japanese Industrialization and Western Imperialist Institutions," Review of Development Economics, May 2014, 18 (2), 254-271.

Ongena, Steven, José-Luis Peydró, and Neeltje van Horen, "Shocks Abroad, Pain at Home? Bank-Firm-Level Evidence on the International Transmission of Financial Shocks," IMF Economic Review, November 2015, 63 (4), 698-750.

Peek, J. and E. S Rosengren, "Collateral Damage: Effects of the Japanese Bank Crisis on Real Activity in the United States," The American Economic Review, 2000, 90 (1), 30-45. 
Peek, Joe and Eric S. Rosengren, "The International Transmission of Financial Shocks: The Case of Japan," The American Economic Review, 1997, 87 (4), pp. 495-505.

Rajan, Raghuram G., "Insiders and Outsiders: The Choice between Informed and Arm'sLength Debt," The Journal of Finance, 1992, 47 (4), 1367-1400.

Rice, Tara and Philip E. Strahan, “Does Credit Competition Affect Small-Firm Finance?” The Journal of Finance, 2010, 65 (3), 861-889.

Sanderson, Eleanor and Frank Windmeijer, "A weak instrument-test in linear IV models with multiple endogenous variables," Journal of Econometrics, 2016, 190 (2), 212 - 221. Endogeneity Problems in Econometrics.

Schnabl, Philipp, "The International Transmission of Bank Liquidity Shocks: Evidence from an Emerging Market," The Journal of Finance, June 2012, 67 (3), 897-932.

Sharpe, Steven A., "Asymmetric Information, Bank Lending and Implicit Contracts: A Stylized Model of Customer Relationships," The Journal of Finance, 1990, 45 (4), pp. 1069-1087.

Shimizu, Yoshinori, "Problems in the Japanese Financial System in the Early 1990s," Hitotsubashi Journal of Commerce and Management, 1992, 27 (1), 29-49.

Staiger, Douglas and James H. Stock, "Instrumental Variables Regression with Weak Instruments," Econometrica, May 1997, 65 (3), 557-586.

Stein, Jeremy C., "Information Production and Capital Allocation: Decentralized versus Hierarchical Firms," The Journal of Finance, 2002, 57 (5), 1891-1921.

Uchida, Hirofumi, Gregory F. Udell, and Wako Watanabe, "Bank size and lending relationships in Japan," Journal of the Japanese and International Economies, June 2008, 22 (2), 242-267. 
Table 1: Descriptive statistics for Japanese prefectures

\begin{tabular}{|c|c|c|c|c|c|}
\hline & \multirow[t]{2}{*}{ Prefecture } & \multirow{2}{*}{$\begin{array}{l}\text { Integrated banks' share } \\
\text { in total lending (pre-1990) }\end{array}$} & \multirow{2}{*}{$\begin{array}{l}\text { manufacturing SME share } \\
\text { in GDP (pre-1990) }\end{array}$} & \multicolumn{2}{|c|}{ post-1990 average growth rates of } \\
\hline & & & & GDP per capita & integrated bank lending \\
\hline 1 & Hokkaido & 49.53 & 9.30 & 1.04 & 8.29 \\
\hline 2 & Aomori & 57.13 & 8.53 & 1.09 & 5.87 \\
\hline 3 & Iwate & 43.05 & 12.26 & 1.46 & 11.60 \\
\hline 4 & Miyagi & 63.97 & 10.77 & 0.82 & 8.23 \\
\hline 5 & Akita & 53.97 & 12.72 & 1.35 & 8.13 \\
\hline 6 & Yamagata & 43.65 & 18.29 & 1.20 & 11.70 \\
\hline 7 & Fukushima & 45.81 & 17.06 & 1.27 & 12.20 \\
\hline 8 & Ibaraki & 55.07 & 19.31 & 0.54 & 11.00 \\
\hline 9 & Tochigi & 58.54 & 20.70 & 0.61 & 10.70 \\
\hline 10 & Gunma & 53.55 & 21.17 & 0.53 & 8.52 \\
\hline 11 & Saitama & 65.37 & 24.47 & 0.46 & 7.89 \\
\hline 12 & Chiba & 59.28 & 13.89 & 0.81 & 11.10 \\
\hline 13 & Tokyo & 86.64 & 7.98 & 0.20 & 3.35 \\
\hline 14 & Kanagawa & 65.46 & 13.84 & 0.02 & 7.79 \\
\hline 15 & Niigata & 49.71 & 17.48 & 1.26 & 10.30 \\
\hline 16 & Toyama & 58.06 & 19.30 & 1.10 & 7.22 \\
\hline 17 & Ishikawa & 60.47 & 17.70 & 1.05 & 5.30 \\
\hline 18 & Fukui & 56.30 & 20.94 & 1.29 & 6.23 \\
\hline 19 & Yamanashi & 42.29 & 20.09 & 0.55 & 7.81 \\
\hline 20 & Nagano & 44.05 & 21.91 & 0.97 & 8.86 \\
\hline 21 & Gifu & 45.97 & 24.68 & 0.85 & 7.26 \\
\hline 22 & Shizuoka & 51.80 & 22.26 & 1.12 & 6.01 \\
\hline 23 & Aichi & 62.18 & 18.08 & 0.65 & 6.16 \\
\hline 24 & Mie & 51.11 & 19.72 & 1.58 & 10.80 \\
\hline 25 & Shiga & 49.05 & 24.86 & 0.53 & 12.60 \\
\hline 26 & Kyoto & 55.23 & 17.85 & 0.92 & 5.55 \\
\hline 27 & Osaka & 77.18 & 19.21 & 0.28 & 4.97 \\
\hline 28 & Hyogo & 55.96 & 17.66 & -0.03 & 7.34 \\
\hline 29 & Nara & 66.14 & 19.67 & 0.77 & 8.58 \\
\hline 30 & Wakayama & 48.40 & 14.95 & 1.77 & 9.66 \\
\hline 31 & Tottori & 50.11 & 12.74 & 0.71 & 9.26 \\
\hline 32 & Shimane & 42.43 & 13.66 & 1.70 & 8.85 \\
\hline 33 & Okayama & 53.36 & 17.90 & 0.48 & 9.35 \\
\hline 34 & Hiroshima & 56.60 & 14.32 & 0.99 & 9.25 \\
\hline 35 & Yamaguchi & 54.63 & 12.16 & 1.45 & 7.85 \\
\hline 36 & Tokushima & 57.62 & 15.36 & 1.58 & 11.90 \\
\hline 37 & Kagawa & 63.06 & 18.00 & 0.86 & 8.29 \\
\hline 38 & Ehime & 50.34 & 16.87 & 1.07 & 10.50 \\
\hline 39 & Kochi & 42.41 & 10.00 & 1.21 & 13.20 \\
\hline 40 & Fukuoka & 65.54 & 10.49 & 0.95 & 7.96 \\
\hline 41 & Saga & 48.21 & 15.81 & 1.79 & 10.40 \\
\hline 42 & Nagasaki & 60.09 & 7.87 & 1.09 & 9.12 \\
\hline 43 & Kumamoto & 49.46 & 9.96 & 0.81 & 12.10 \\
\hline 44 & Oita & 48.69 & 10.39 & 1.61 & 9.59 \\
\hline 45 & Miyazaki & 47.91 & 10.68 & 1.70 & 8.35 \\
\hline 46 & Kagoshima & 44.13 & 9.48 & 1.63 & 8.31 \\
\hline & Mean & 54.55 & 15.92 & 0.99 & 8.81 \\
\hline & Std. Deviation & 9.16 & 4.74 & 0.46 & 2.21 \\
\hline
\end{tabular}

Note: all numbers in percent. Core prefectures highlighted in bold. 
Table 2: The 'silken thread' — banking integration in 1990 and silk filatures in 1895

\begin{tabular}{|c|c|c|c|c|}
\hline & \multicolumn{4}{|c|}{ Financial Integration } \\
\hline & \multicolumn{4}{|c|}{ pre-1990 share in prefecture-level lending by } \\
\hline & \multicolumn{2}{|c|}{ Integrated Banks } & \multicolumn{2}{|c|}{ Local Banks } \\
\hline $\begin{array}{l}\text { filatures / population } \\
\qquad(\log \#)\end{array}$ & $\begin{array}{l}-0.03 \\
(-3.14)\end{array}$ & $\begin{array}{l}-0.04 \\
(-4.70)\end{array}$ & $\begin{array}{c}0.03 \\
(4.22)\end{array}$ & $\begin{array}{c}0.03 \\
(4.11)\end{array}$ \\
\hline Relative GDP (pre-90) & & $\begin{array}{c}0.19 \\
(3.35)\end{array}$ & & $\begin{array}{l}-0.01 \\
(-0.20)\end{array}$ \\
\hline Core Dummy & & $\begin{array}{c}0.07 \\
(2.46)\end{array}$ & & $\begin{array}{l}-0.001 \\
(-0.02)\end{array}$ \\
\hline $\begin{array}{l}\text { Distance to Yokohama } \\
\qquad(\log )\end{array}$ & & $\begin{array}{l}-0.02 \\
(-1.30)\end{array}$ & & $\begin{array}{c}0.01 \\
(0.65)\end{array}$ \\
\hline$R^{2}$ & 0.18 & 0.64 & 0.29 & 0.30 \\
\hline \multicolumn{5}{|c|}{$\begin{array}{l}\text { The Table shows regressions of modern-day (1980-90 average) prefectural lend- } \\
\text { ing shares by bank type on the (log) number of filatures per head of population } \\
\text { in a prefecture in } 1895 \text {. Integrated banks include mega ('city') banks as well as } \\
\text { Tier } 1 \text { regional banks, local banks are Tier } 2 \text { regional banks (Sogo) and local co- } \\
\text { operative banks (Shinkin). The control variables are relative (1980-90 average) } \\
\text { per capita GDP, the (log) distance to Yokohama and a dummy for the core areas } \\
\text { (Tokyo, Osaka, Aichi, Kanagawa, Chiba, Saitama, Hyogo and Kyoto prefectures), } \\
\text { t-statistics in parentheses. Constants not reported. }\end{array}$} \\
\hline
\end{tabular}


Table 3: The Credit Reallocation Channel: baseline (OLS) results

\begin{tabular}{|c|c|c|c|}
\hline & \multicolumn{3}{|c|}{ Lending by ... } \\
\hline & all banks & integrated banks & local banks \\
\hline & (1) & (2) & (3) \\
\hline \multirow[t]{2}{*}{$\mathrm{SME}^{k} \times \mathrm{FI}^{k} \mathrm{SHOCK}_{t}$} & 2.67 & 3.27 & 1.39 \\
\hline & $(4.18)$ & $(4.36)$ & $(1.26)$ \\
\hline \multirow[t]{2}{*}{$\mathrm{FI}^{k} \mathrm{SHOCK}_{t}$} & -0.52 & -0.60 & -0.34 \\
\hline & $(-5.63)$ & $(-7.06)$ & $(-2.04)$ \\
\hline \multirow{2}{*}{$\mathrm{SME}^{k} \mathrm{SHOCK}_{t}$} & -1.62 & -1.99 & -0.88 \\
\hline & $(-3.71)$ & $(-3.48)$ & $(-1.40)$ \\
\hline \multirow[t]{2}{*}{ predicted output growth } & 0.38 & 0.03 & 0.18 \\
\hline & $(1.17)$ & $(0.07)$ & $(0.34)$ \\
\hline \multirow[t]{2}{*}{ local land price growth } & 0.00 & 0.02 & -0.04 \\
\hline & $(0.17)$ & $(0.50)$ & $(-0.48)$ \\
\hline \multirow[t]{2}{*}{ local land price growth $\times \mathrm{SME}^{k}$} & 0.00 & -0.01 & 0.14 \\
\hline & $(0.02)$ & $(-0.07)$ & $(0.28)$ \\
\hline \multirow[t]{2}{*}{ Local bank real estate exposure $\times \mathrm{SHOCK}_{t}$} & 0.03 & 0.07 & -0.00 \\
\hline & $(0.38)$ & $(0.65)$ & $(-0.04)$ \\
\hline \multirow[t]{2}{*}{ Distance to Yokohama $\times \mathrm{SHOCK}_{t}$} & -0.00 & -0.00 & -0.00 \\
\hline & $(-0.96)$ & $(-0.37)$ & $(-0.60)$ \\
\hline \multirow[t]{2}{*}{ CoreDummy $\times \mathrm{SHOCK}_{t}$} & -0.05 & -0.06 & -0.03 \\
\hline & $(-2.91)$ & $(-5.50)$ & $(-1.84)$ \\
\hline Observations & 736 & 736 & 736 \\
\hline Adjusted $\mathrm{R}^{2}$ & 0.60 & 0.78 & 0.71 \\
\hline
\end{tabular}

NOTES: The table shows OLS results for our reduced-form specifications (5) $\triangle$ OUTCOME $_{t}^{k}=$ $\left[\alpha_{0} \times \mathrm{SME}^{k} \times \mathrm{FI}^{k}+\alpha_{1} \times \mathrm{FI}^{k}+\alpha_{2} \times \mathrm{SME}^{k}+\boldsymbol{\alpha}_{3}^{\prime} X^{k}\right] \times \mathrm{SHOCK}_{t}+\mu^{k}+\tau_{t}+\boldsymbol{b}^{\prime} Z_{t}^{k}+\nu_{t}^{k}$ where $\Delta$ OUTCOME $_{t}^{k}$ stands for aggregate prefecture-level lending growth by all banks (column (1)), integrated banks (column (2)) and local banks (column (3)). SHOCK ${ }_{t}$ is the (negative) land price growth in the core prefectures, $\mathrm{SME}^{k}$ is small-business importance based on the SME share in total employment in prefecture $k, \mathrm{FI}^{k}$ is the measure of regional banking integration, $X^{k}$ and $Z_{t}^{k}$ are vectors of additional controls and $\mu^{k}$ and $\tau_{t}$ are prefecture-fixed and time effects respectively. The sample period is 1980-96. Standard errors are clustered by prefecture and year, t-statistics in parentheses. 
Table 4: The Credit Reallocation Channel: IV evidence

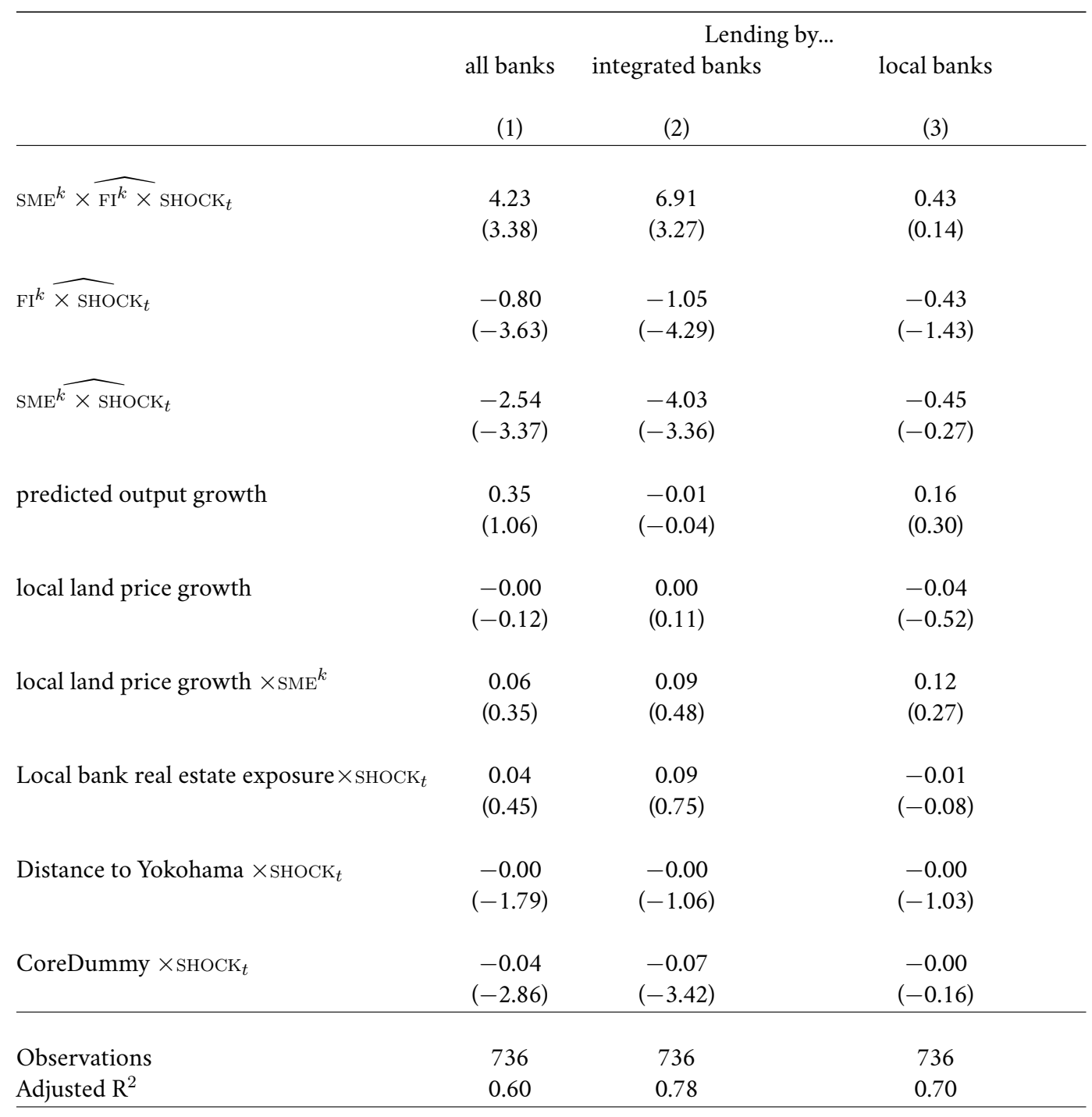

Memorandum Items:

$$
\begin{aligned}
& \text { Share SMEs with City main bank }{ }^{k} 2002=\underset{(5.03)}{0.62} \times \mathrm{FI}_{1980-90}^{k}+0.08\left(R^{2}=0.49\right) \\
& \text { SME share among City bank customers }{ }^{k}=\underset{(1.74)}{0.067} \times \operatorname{SME}_{1980-90}^{k}+0.95\left(R^{2}=0.04\right)
\end{aligned}
$$

NOTES: The table shows IV results for the specification

$$
\Delta \text { OUTCOME }_{t}^{k}=\alpha_{0} \times \mathrm{SME}^{k} \times \widehat{\mathrm{FI}^{k} \times \mathrm{SHOCK}_{t}}+\alpha_{1} \times \mathrm{FI}^{k} \widehat{\times \mathrm{SHOCK}_{t}}+\alpha_{2} \times \mathrm{SME}^{k} \times \mathrm{SHOCK}_{t}+\text { Controls }
$$

where $\Delta$ OUTCOME $_{t}^{k}$ is aggregate prefecture-level lending growth for all banks (column (1)), integrated banks (column (2)) and local banks (column (3)). The regression uses $\mathrm{SME}^{k} \times \mathrm{SILK}^{k} \times \mathrm{SHOCK}_{t}$ and $\mathrm{SILK}^{k} \times \mathrm{SHOCK}_{t}$ as instruments, where $\mathrm{SILK}^{k}$ is the number of silk filatures per head in prefecture $k$ in 1895 . As before, $\mathrm{SHOCK}_{t}$ is the (negative) land price growth in the core prefectures, $\mathrm{SME}^{k}$ is small-business importance based on the SME share in total employment in prefecture $k, \mathrm{FI}^{k}$ is the measure of regional banking integration, $X^{k}$ and $Z_{t}^{k}$ are vectors of additional controls and $\mu^{k}$ and $\tau_{t}$ are prefecture-fixed and time effects respectively. The sample period is 1980-1996. Standard errors are clustered by prefecture and year, $t$-statistics appear in parentheses.

The memorandum items at the bottom of the table report I) a cross-sectional regression of the fraction of small firms reporting a city bank as main bank in the 2002 survey of enterprise finance (SEF) on $\mathrm{FI}^{k}$ II) a cross-sectional regressions of the fraction of SMEs among corporate customers of city banks in the 2006 TSR data set on SME ${ }^{k}$. The t-statistics based on robust (HC) standard errors appear in parentheses. 
Table 5: Instrumental Variables: First Stage

\begin{tabular}{|c|c|c|}
\hline & \multicolumn{2}{|c|}{ Dep. variable } \\
\hline & $\begin{array}{c}\mathrm{SME}^{k} \times \mathrm{FI}^{k} \times \mathrm{SHOCK}_{t} \\
\text { (1) }\end{array}$ & $\begin{array}{c}\mathrm{FI}^{k} \times \mathrm{SHOCK}_{t} \\
(2)\end{array}$ \\
\hline $\operatorname{SME}^{k} \times \operatorname{SILK}^{k} \mathrm{SHOCK}_{t}$ & $\begin{array}{l}-0.03 \\
(-3.21)\end{array}$ & $\begin{array}{c}0.12 \\
(1.22)\end{array}$ \\
\hline $\operatorname{SILK}^{k} \times$ SHOCK $_{t}$ & $\begin{array}{l}-0.00 \\
(-1.72)\end{array}$ & $\begin{array}{l}-0.07 \\
(-4.10)\end{array}$ \\
\hline $\mathrm{SME}^{k} \times \mathrm{SHOCK}_{t}$ & $\begin{array}{c}0.72 \\
(20.04)\end{array}$ & $\begin{array}{l}-0.06 \\
(-0.14)\end{array}$ \\
\hline predicted output growth & $\begin{array}{l}-0.01 \\
(-0.79)\end{array}$ & $\begin{array}{l}-0.11 \\
(-1.20)\end{array}$ \\
\hline local land price growth & $\begin{array}{l}0.00 \\
(0.15)\end{array}$ & $\begin{array}{l}-0.02 \\
(-1.13)\end{array}$ \\
\hline local land price growth $\times \mathrm{SME}^{k}$ & $\begin{array}{l}-0.00 \\
(-0.40)\end{array}$ & $\begin{array}{c}0.14 \\
(1.38)\end{array}$ \\
\hline Local bank real estate exposure $\times \mathrm{SHOCK}_{t}$ & $\begin{array}{l}-0.01 \\
(-0.50)\end{array}$ & $\begin{array}{l}0.07 \\
(0.72)\end{array}$ \\
\hline Distance to Yokohama $\times \mathrm{SHOCK}_{t}$ & $\begin{array}{l}-0.00 \\
(-2.35)\end{array}$ & $\begin{array}{l}-0.00 \\
(-3.81)\end{array}$ \\
\hline CoreDummy $\times \mathrm{SHOCK}_{t}$ & $\begin{array}{c}0.01 \\
(9.31) \\
\end{array}$ & $\begin{array}{c}0.10 \\
(9.00) \\
\end{array}$ \\
\hline $\begin{array}{l}\text { Observations } \\
\text { Adjusted } \mathrm{R}^{2}\end{array}$ & $\begin{array}{l}736 \\
0.99\end{array}$ & $\begin{array}{l}736 \\
0.99\end{array}$ \\
\hline $\begin{array}{l}\text { First stage F-stat (robust) } \\
\text { Kleibergen Paap rk statistics (robust) } \\
\text { Kleibergen Paap rk statistics (clustered) } \\
\text { cond. F-statistics (robust) } \\
\text { cond. F-statistics (clustered) }\end{array}$ & $\begin{array}{c}214.3(\mathrm{p}<0.01) \\
16.81 \\
2.84 \\
127.57(\mathrm{p}<0.01) \\
24.15(\mathrm{p}<0.01)\end{array}$ & $\begin{array}{c}165.4(\mathrm{p}>0.01) \\
\quad(\mathrm{p}<0.01) \\
(\mathrm{p}=0.02) \\
60.57(\mathrm{p}<0.01) \\
11.68(\mathrm{p}<0.01)\end{array}$ \\
\hline
\end{tabular}

NOTES: The table reports the first-stage regressions for the two endogenous variables, $\mathrm{SME}^{k} \times \mathrm{FI}^{k} \mathrm{SHOCK}_{t}$ and $\mathrm{FI}^{k} \mathrm{SHOCK}_{t}$ based on the sample period 1980-1996. $t$-statistics based on robust standard errors appear in parentheses below the coefficients. At the bottom of the table we report the first-stage F-statistics on the excluded instruments, the Kleibergen and Paap (2006) rk rank statistics along with the associated p-values for the hypothesis of under-identification as well as the conditional F-statistics by Sanderson and Windmeijer (2016), each for robust (HAC) and clustered standard errors. P-values in parentheses. Those for the conditional F-stats are bootstrapped using the condf stat routine provided in the R package ' $\mathrm{ffe}$ ' (Gaure $(2013,2019))$. 
Table 6: Impact on local interest rate differentials

\begin{tabular}{|c|c|c|}
\hline & \multicolumn{2}{|c|}{$\begin{array}{l}\text { Dep variables: lending rates of local banks } \\
\text { market power of integrated banks }\end{array}$} \\
\hline & low & high \\
\hline Local bank real estate exposure $\times \mathrm{SHOCK}_{t}$ & $\begin{array}{c}0.03 \\
(2.58)\end{array}$ & $\begin{array}{c}0.00 \\
(0.15)\end{array}$ \\
\hline Observations & 326 & 336 \\
\hline Adjusted $\mathrm{R}^{2}$ & 0.98 & 0.98 \\
\hline Controls & YES & YES \\
\hline
\end{tabular}

NOTES: The table shows OLS regression of local banks interest rates on the interaction between the aggregate land price decline, $\mathrm{SHOCK}_{t}$, and the pre-1991 share of real estate lending on local banks' balance sheets and our full set of controls from the previous tables. The first (second) column is for prefectures where integrated banks have an above (below) median share of the local SME lending market. The sample period is 1980-1996. Controls are the same as in the lending growth regressions in Tables 3 and 4. Coefficients for control variables are not reported. Standard errors are clustered by year and prefecture, numbers in parentheses are $t$-statistics. The share of integrated banks in local lending markets is measured by the share of SMEs reporting an integrated bank as their main bank connection in the 2002 Survey of Enterprise Finance. 
Table 7: Credit Reallocation and Output Growth- OLS and IV results

Dependent variable is prefecture-level GDP growth

OLS IV

(1)

$\begin{array}{lcc}\mathrm{SME}^{k} \times \mathrm{FI}^{k} \text { SHOCK }_{t} & 0.91 & 1.86 \\ & (2.21) & (2.29) \\ & & \\ \mathrm{FI}^{k} \text { SHOCK }_{t} & -0.19 & -0.34 \\ & (-3.60) & (-2.96) \\ \mathrm{SME}^{k} \text { SHOCK }_{t} & -0.52 & -1.07 \\ & (-1.83) & (-2.32)\end{array}$

$\begin{array}{lll}\text { Controls } & \text { YES }\end{array}$

Observations $\quad 1,150 \quad 1,150$

$\begin{array}{lll}\text { Adjusted } \mathrm{R}^{2} & 0.69 & 0.69\end{array}$

NOTES: The table shows OLS (column (1)) and IV (column (2)) results for our reduced-form specifications (5) $\Delta \operatorname{GDP}_{t}^{k}=$ $\left[\alpha_{0} \times \mathrm{SME}^{k} \times \mathrm{FI}^{k}+\alpha_{1} \times \mathrm{FI}^{k}+\alpha_{2} \times \mathrm{SME}^{k}+\boldsymbol{\alpha}_{3}^{\prime} X^{k}\right] \times \mathrm{SHOCK}_{t}+\mu^{k}+\tau_{t}+$ $\boldsymbol{b}^{\prime} Z_{t}^{k}+\nu_{t}^{k}$ where $\Delta \mathrm{GDP}_{t}^{k}$ stands for aggregate prefecture-level output growth SHOCK $_{t}$ is the (negative) land price growth in the core prefectures, $\mathrm{SME}^{k}$ is small-business importance based on the SME share in total employment in prefecture $k, \mathrm{FI}^{k}$ is the measure of regional banking integration, $X^{k}$ and $Z_{t}^{k}$ are vectors of additional controls and $\mu^{k}$ and $\tau_{t}$ are prefecture-fixed and time effects respectively. The sample period is 1980-2005. Standard errors are clustered by prefecture and year, t-statistics in parentheses. Controls are the same as in the lending growth regressions in Tables 3 and 4. Coefficients for control variables are not reported. In the IV-regression, $\mathrm{SME}^{k} \times \mathrm{FI}^{k} \mathrm{SHOCK}_{t}$ and $\mathrm{FI}^{k} \mathrm{SHOCK}_{t}$ are instrumented using $\mathrm{SME}^{k} \times \mathrm{SILK}^{k} \mathrm{SHOCK}_{t}$ and $\mathrm{SILK}^{k} \mathrm{SHOCK}_{t}$, as in Table 5 
Table 8: Reallocation and Output Synchronization

Dependent variable is output synchronization

$\operatorname{SYNC}(1)$

$\operatorname{SYNC}(2)$

$\begin{array}{lcc}\mathrm{SME}^{k} \times \mathrm{FI}^{k} \text { SHOCK }_{t} & 0.57 & 0.66 \\ & (1.88) & (2.80) \\ & & \\ \mathrm{FI}^{k} \text { SHOCK }_{t} & -0.04 & -0.03 \\ & (-0.93) & (-0.97) \\ & & -0.31 \\ \mathrm{SME}^{k} \text { SHOCK }_{t} & -0.27 & (-2.16) \\ & (-1.40) & \text { YES } \\ \text { Controls } & \text { YES } & 1,150 \\ & & 0.25\end{array}$

NOTES: The table shows results for reduced-form specifications (5) $\operatorname{SYNC}(i)_{t}^{k}=$ $\left[\alpha_{0} \times \mathrm{SME}^{k} \times \mathrm{FI}^{k}+\alpha_{1} \times \mathrm{FI}^{k}+\alpha_{2} \times \mathrm{SME}^{k}+\boldsymbol{\alpha}_{3}^{\prime} X^{k}\right] \times \mathrm{SHOCK}_{t}+\mu^{k}+\tau_{t}+$ $\boldsymbol{b}^{\prime} Z_{t}^{k}+\nu_{t}^{k}$ where $\operatorname{SYNC}(i)_{t}^{k}=-\left|v_{t}^{k}\right|$ for $i=1,2$ stands for the synchronization of prefecture-level output growth with country-wide output growth and $v_{t}^{k}$ is the residual of the regression

$$
\Delta \operatorname{GDP}_{t}^{k}=\operatorname{COUNTRY}_{t}+\mathrm{PREF}^{k}+v_{t}^{k}
$$

andCOUNTRY $_{t}$ is a time fixed effects for $i=1$ and a post-1991 dummy for $i=2$. See discussion in main text. $\mathrm{SHOCK}_{t}$ is the (negative) land price growth in the core prefectures, $\mathrm{SME}^{k}$ is small-business importance based on the SME share in total employment in prefecture $k, \mathrm{FI}^{k}$ is the measure of regional banking integration, $X^{k}$ and $Z_{t}^{k}$ are vectors of additional controls and $\mu^{k}$ and $\tau_{t}$ are prefecture-fixed and time effects respectively. The sample period is 1980-2005. Standard errors are clustered by prefecture and year, t-statistics in parentheses. Controls are the same as in the lending growth regressions in Tables 3 and 4. Coefficients for control variables are not reported. 
Table 9: Credit Reallocation and the firm borrowing channel

(1)

Bank Lending Channel
only
(2)

Reallocation \& Bank Lending Channels

(IV using FI)
(IV using FI)
(3)

Reallocation \&

Bank Lending Channels

(IV using SILK)

\begin{tabular}{lccc}
$\widehat{\Delta \text { Lending }_{t}^{k}}$ & 0.50 & 0.40 & 0.34 \\
& $(7.20)$ & $(4.62)$ & $(3.46)$ \\
Controls & YES & YES & YES \\
& & & \\
Observations & 736 & 736 & 736 \\
Adjusted R & & 0.43 & 0.46 \\
\hline
\end{tabular}

NOTES: The table shows IV estimates of the firm-borrowing coefficient $\gamma$ in the structural equation (3) $\Delta \operatorname{GDP}_{t}^{k}=\gamma \times \widehat{\Delta \text { Lending }_{t}^{k}}+\eta_{t}^{k}+\mu^{k}+\tau_{t} . \Delta$ Lending $_{t}^{k}$ is instrumented in three different ways. In column (1) we instrument it with the fitted value of a regression of integrated banks' lending growth on $\mathrm{FI}^{k} \times$ SHOCK$_{t}$. In column (2), we use the fitted value from the regression of integrated banks' lending growth on $\mathrm{SME}^{k} \times \mathrm{FI}^{k} \times \mathrm{SHOCK}_{t}, \mathrm{FI}^{k} \times \mathrm{SHOCK}_{t}$ (corresponding to column (2) of Table 3). In column (3) the instrument is the fitted value of the regression of integrated banks' lending growth on $\mathrm{SME}^{k} \times \mathrm{SILK}^{k} \times \mathrm{SHOCK}_{t}$, $\mathrm{SILK}^{k} \times \mathrm{SHOCK}_{t}$ (corresponding to column (2) of Table 4). Standard errors are clustered by time and prefecture, $\mathrm{t}$-statistics in parentheses. Sample period is 1980-96. All regressions contain our full set of controls as shown in Table 3 and 4. The coefficients of these controls are not separately reported. 


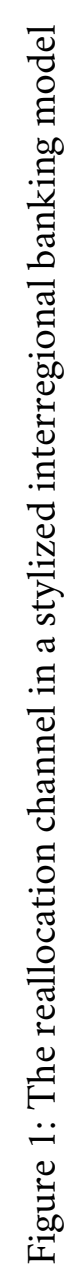

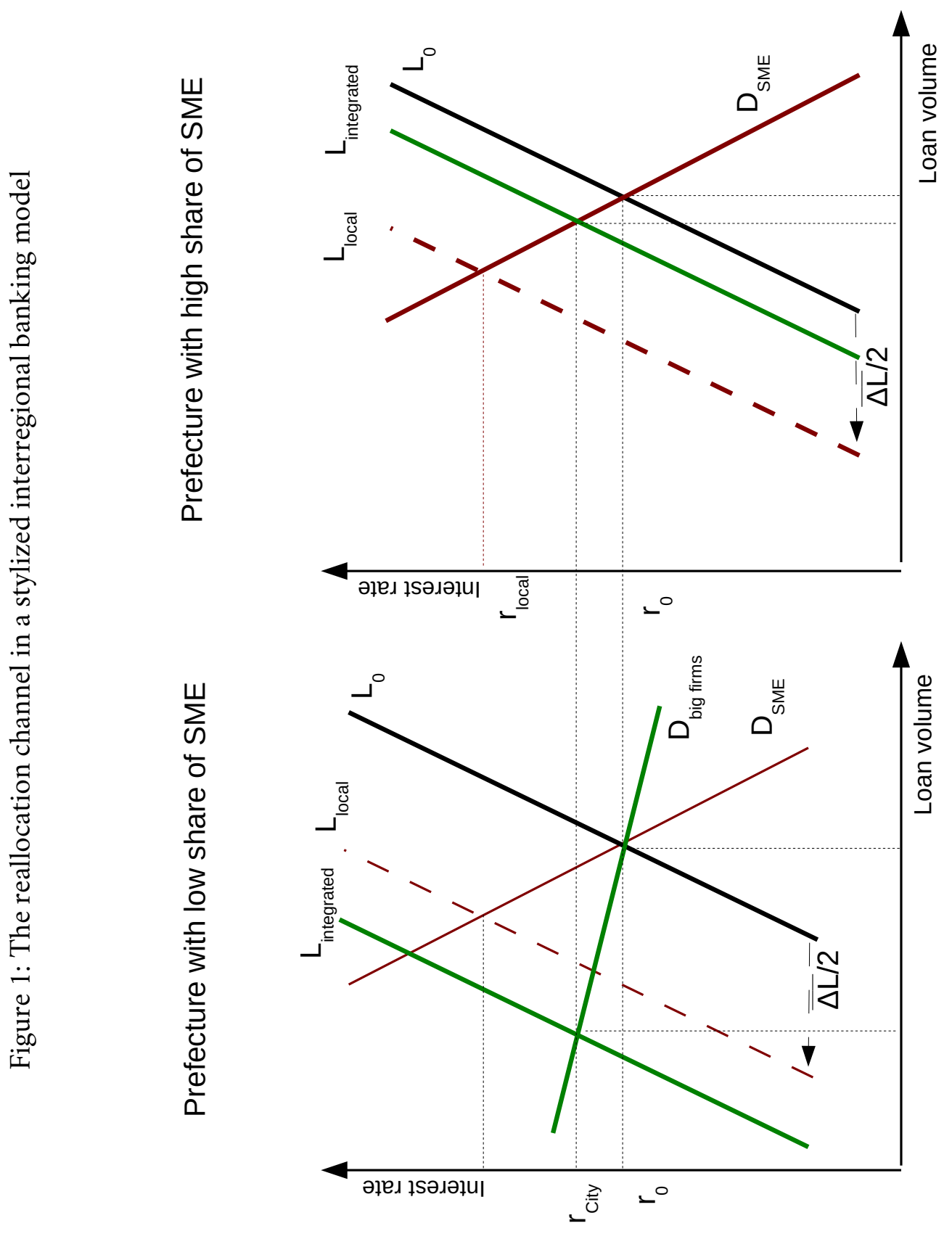

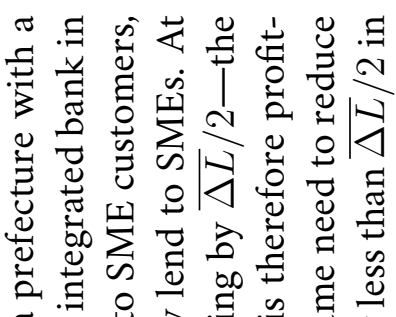

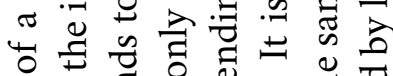

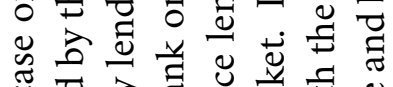

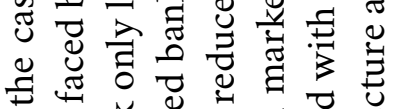

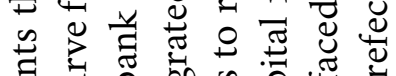
ब $气$ कू

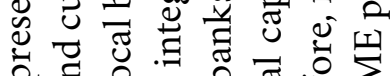

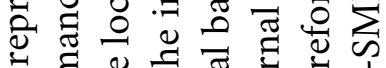
¿

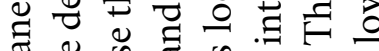
బ

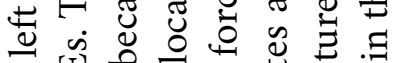
Q

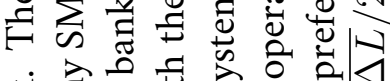

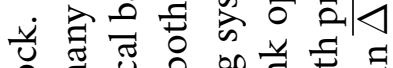

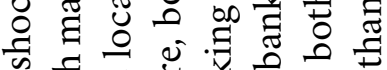

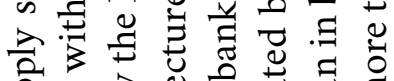

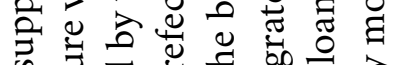

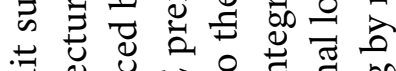
:

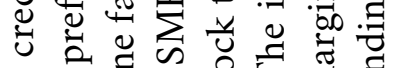

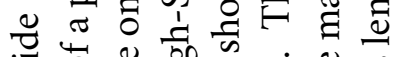

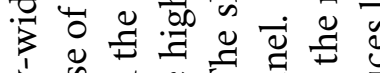

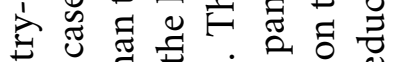

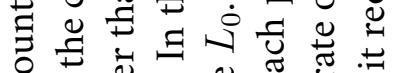
ठ

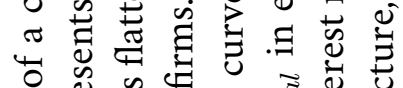
पे

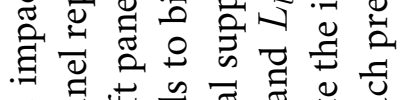

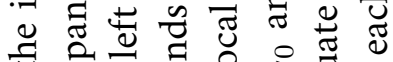

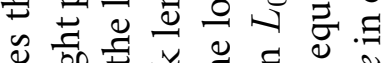

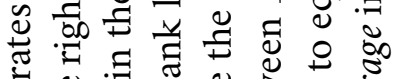

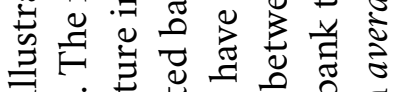

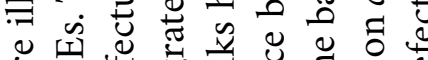

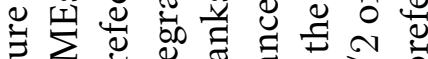

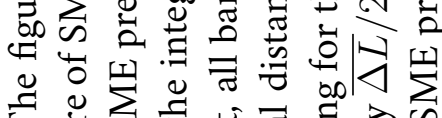

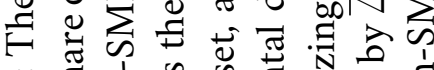

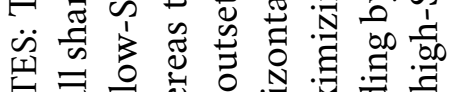

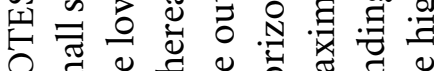

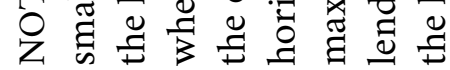


Figure 2: The 'Silken Thread'

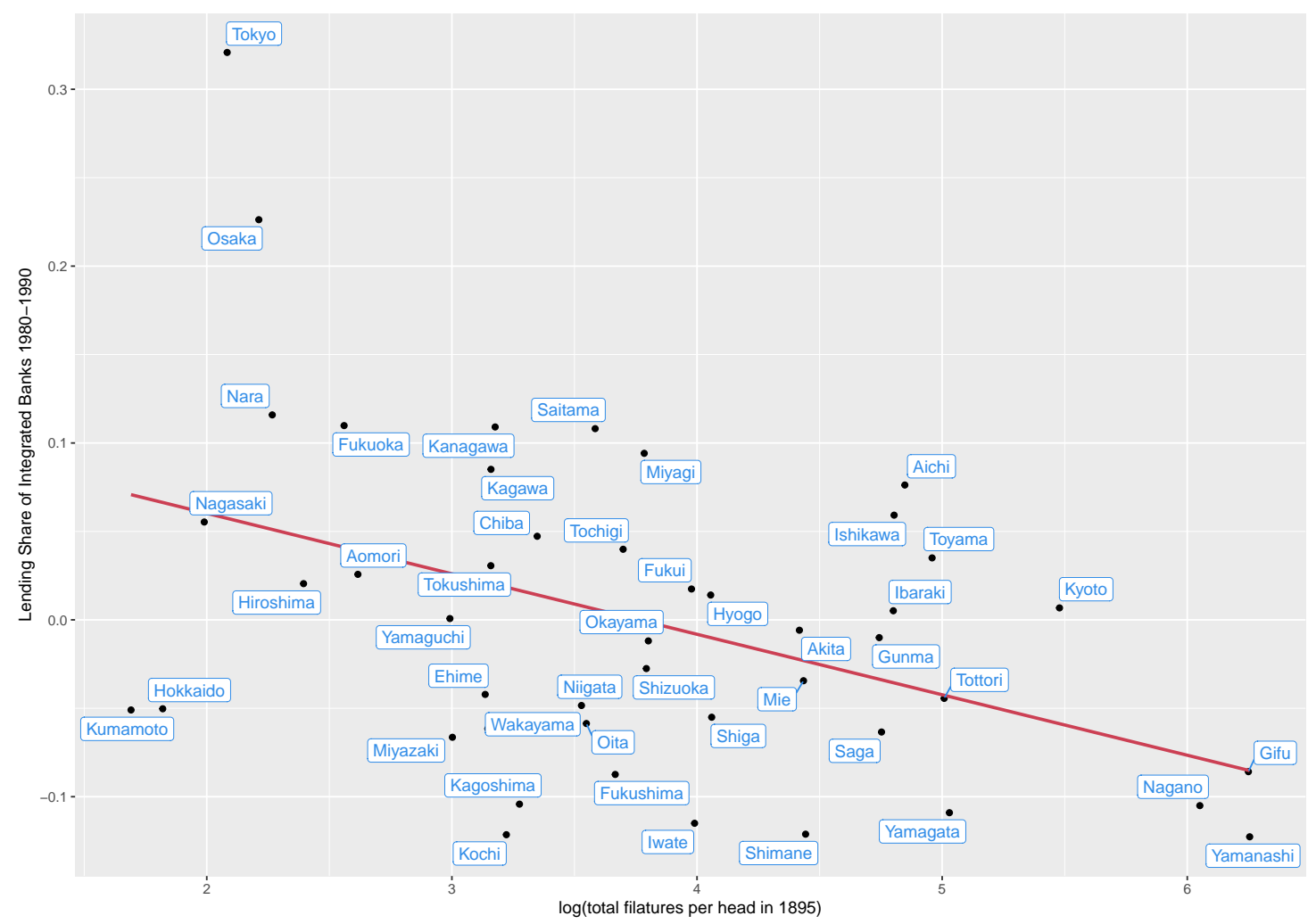

NOTES: the figure shows prefecture-level integrated bank lending shares (1980-1990 averages) vs. the log of the number of silk filatures per head in 1895 . 

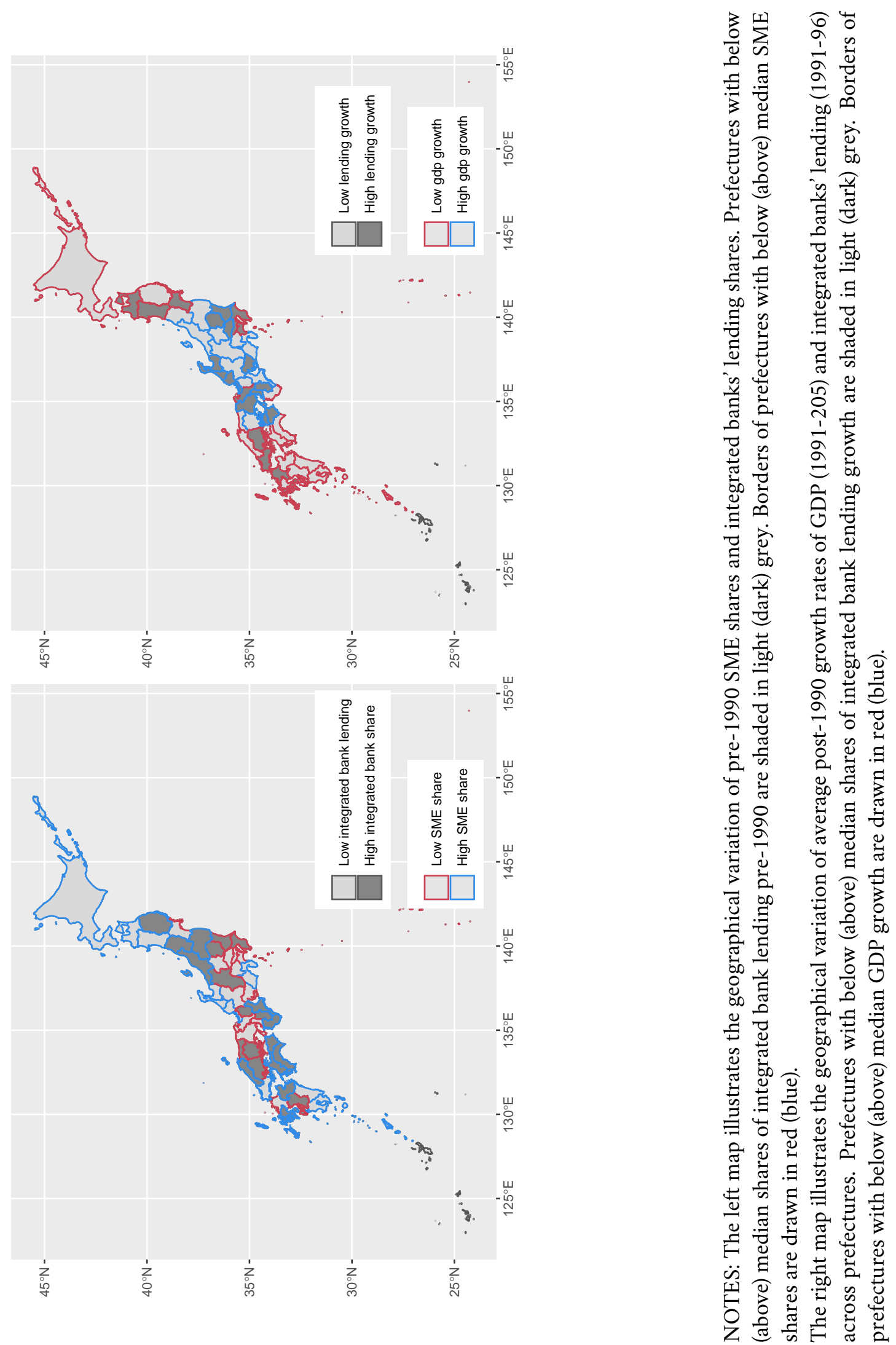
Figure 4: Magnitude and geographical incidence of reallocation and bank lending channel, 1991-96

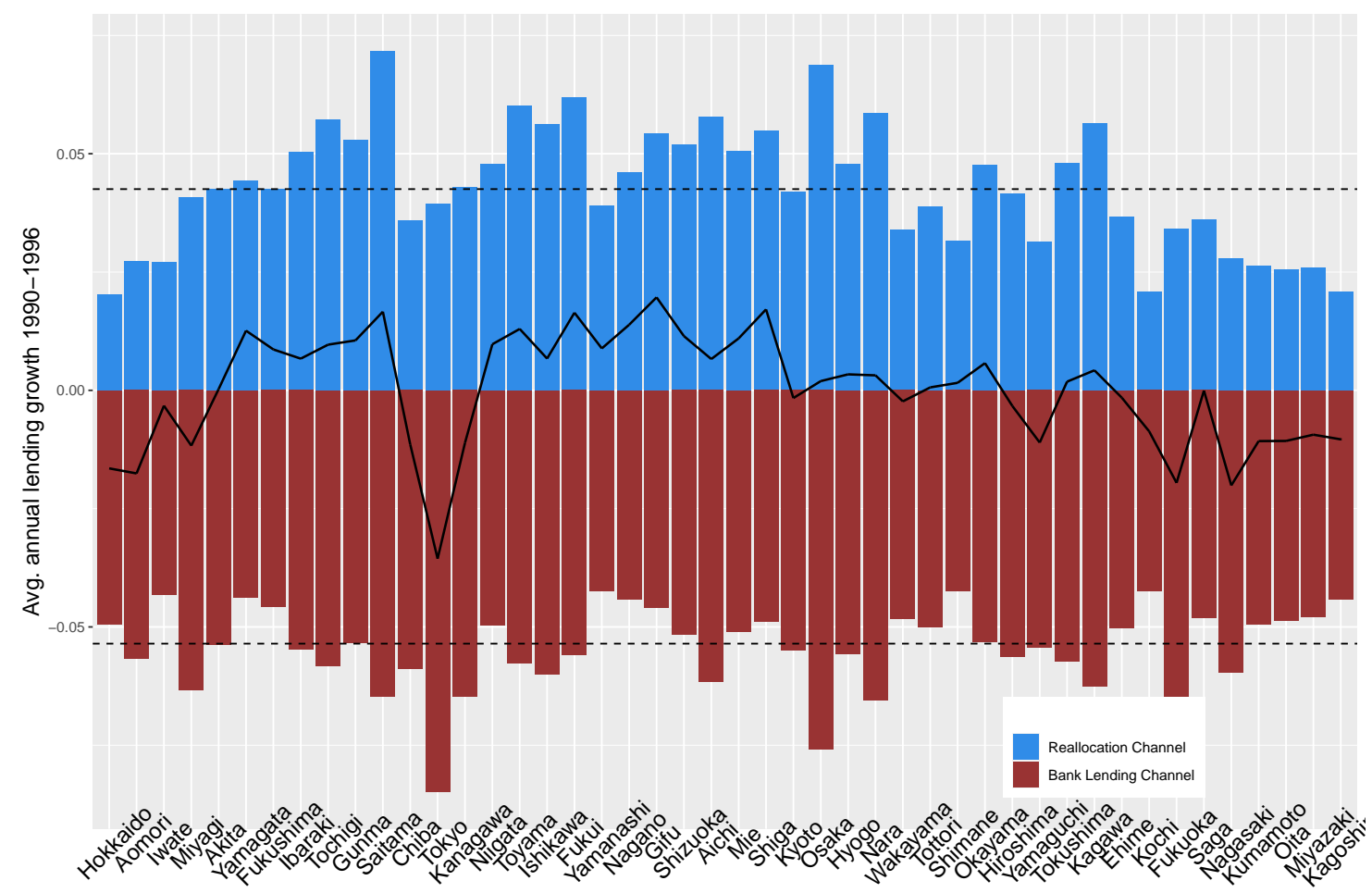

\section{NOTES:}

The figure illustrates the magnitude of the reallocation and bank lending channels and their geographical heterogeneity. The bars indicate the average annual 1991-96 growth rate of integrated banks' lending implied by the reallocation channel (blue) and the bank-lending channel (red) as predicted from our OLS regressions in column (2) of Table 3 and calculated according to equations (9) and (10) respectively. . The black solid line is the sum of the two effects. The upper (lower) horizontal dotted lines gives the mean across prefectures of the reallocation (bank lending) channel respectively.

Prefectures are ordered based on their official numbering, starting in the northeast (Hokkaido, number 1) and ending in the south-west of the country (Kagoshima, number 46). 
Figure 5: Geographical credit reallocation—net flows of integrated bank lending, 1991-96

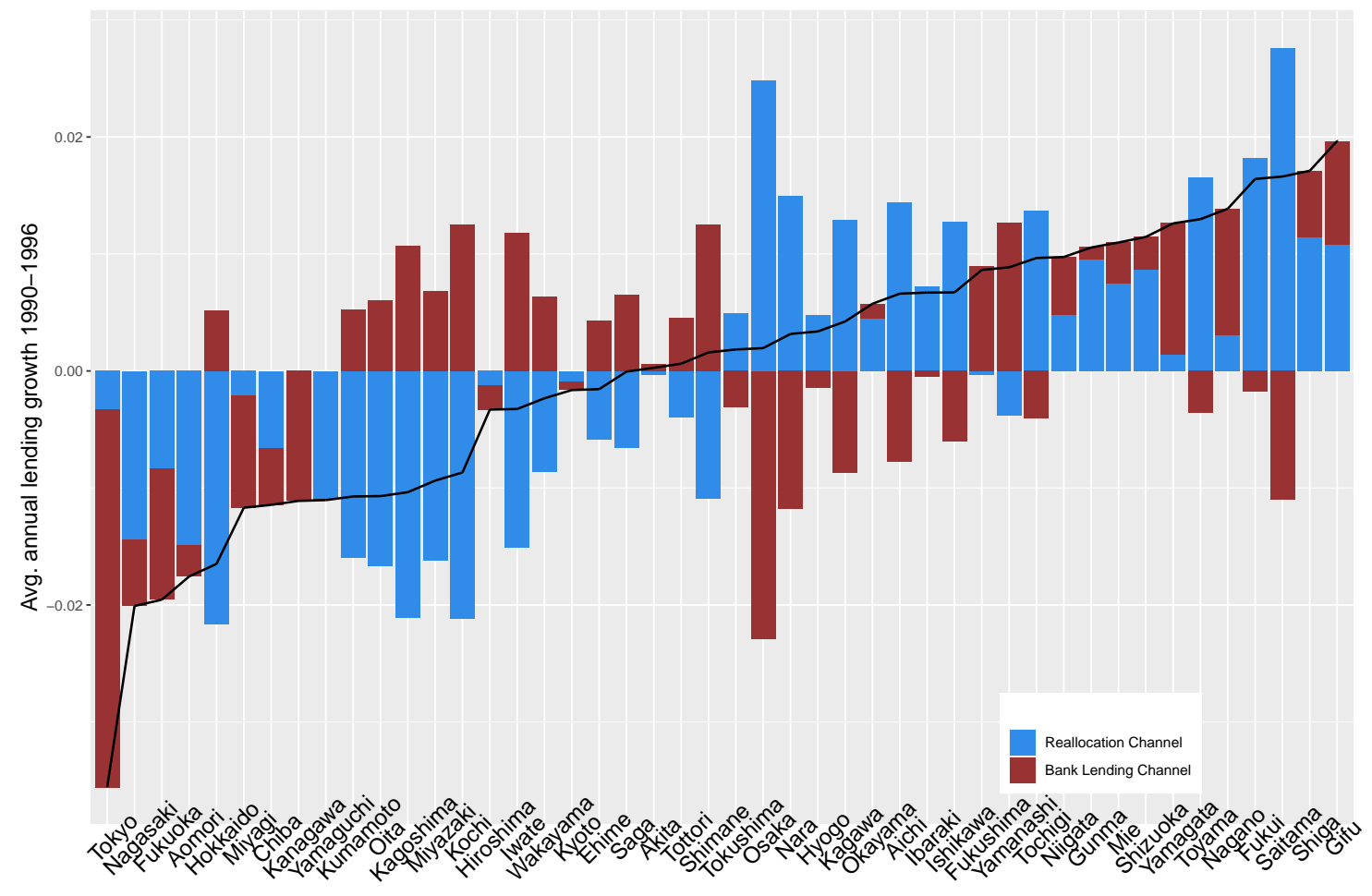

\section{NOTES:}

The figure illustrates the geographical reallocation of credit by intgerated banks. It orders prefectures in ascending order according to the average annual net flows (relative to the country-wide mean, over the period 1990-96) of integrated bank lending implied by our OLS estimates in column (2) of Table 3. The black solid line is the net flow, blue (red) bars indicate the net contribution of the reallocation (bank lending) channels respectively. 
Figure 6: Output response conditional on SME share in high/low FI prefectures

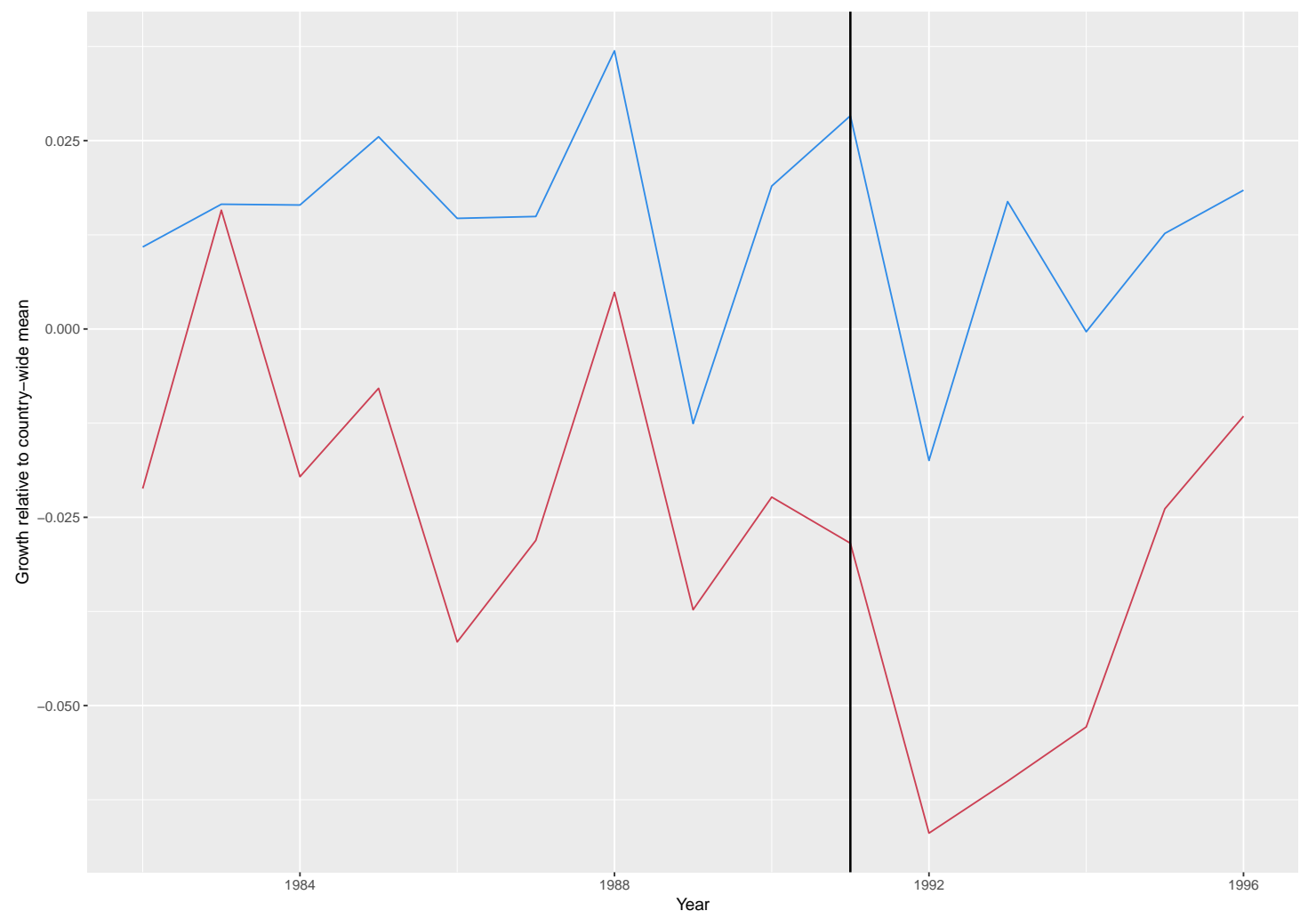

NOTES:

The figure illustrates how financial integration mitigated the impact of the land price decline on prefectures with bank-dependent SMEs. We split prefectures into two groups depending on their banking integration ( above (below) median FI).For each group, we then run the regression

$$
\Delta \mathrm{GDP}_{t}^{k}=\eta_{t} \times \mathrm{SME}^{k} \times \mathrm{YEAR}_{t}+\mathrm{YEAR}_{t}+\mathrm{PREF}^{k}
$$

The figure plots the predicted output growth conditional on an average SME share (relative to the countrywide mean) for each group of prefectures. This is constructed as the sequence $\eta_{t} \times$ SME $^{\text {median }}$ where $\mathrm{SME}^{\text {median }}$ is the pre-1991 median SME share across all prefectures. Results for the high (low) FI group appear in blue (red). 


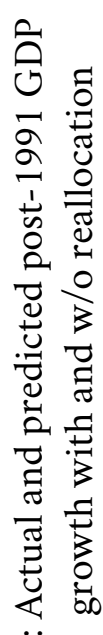

章

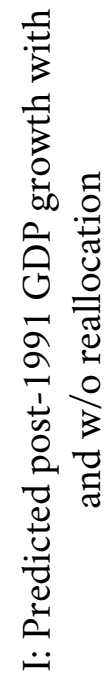

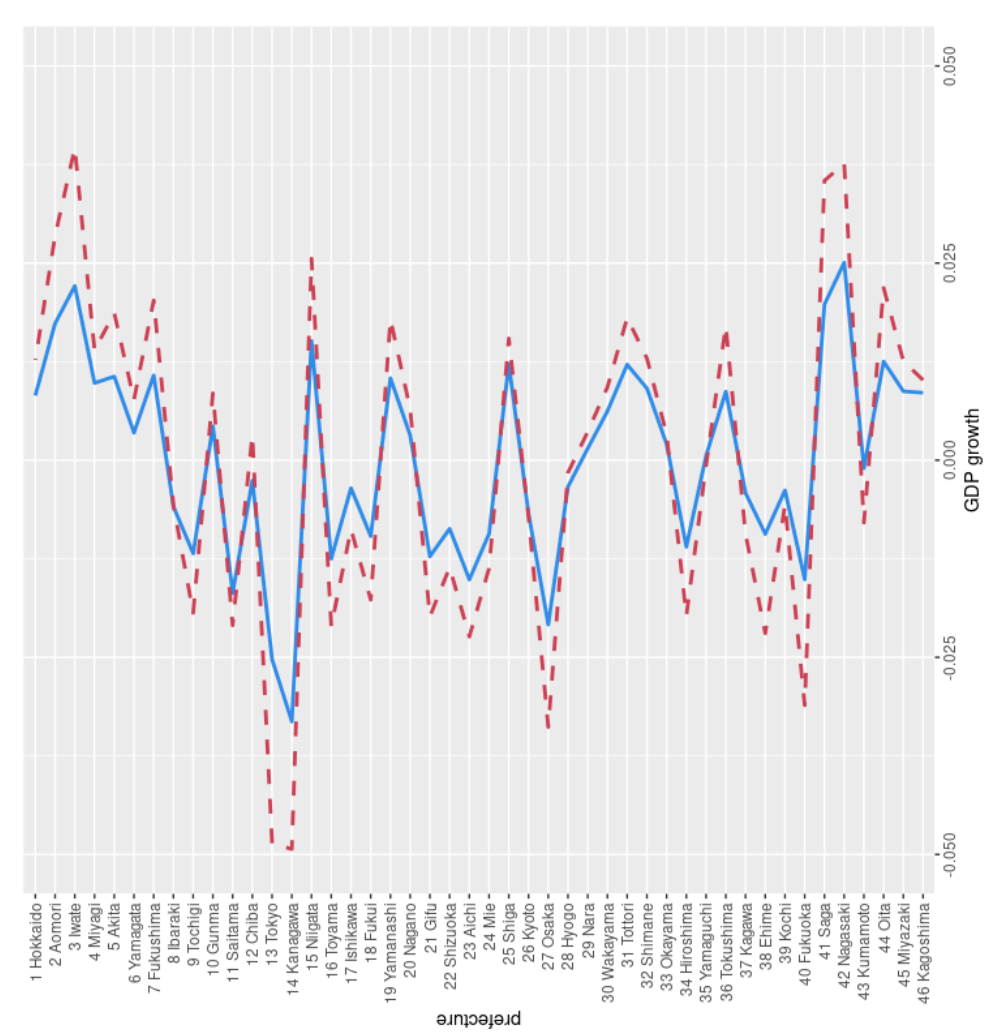

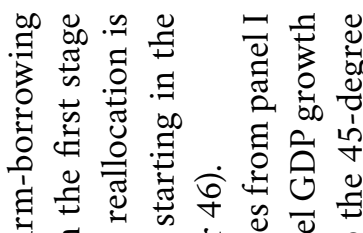

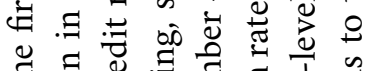

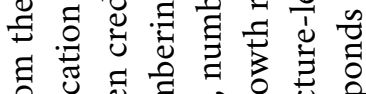

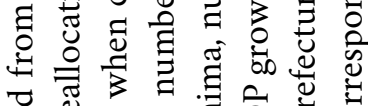

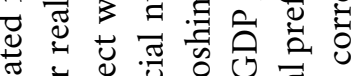

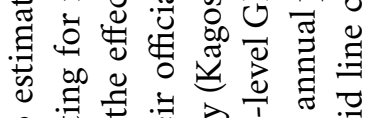

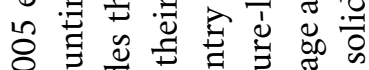

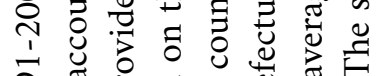
ลे 0 范

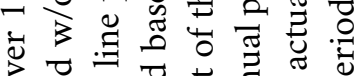

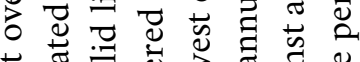

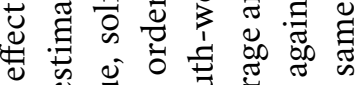

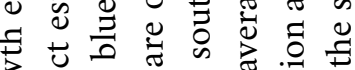

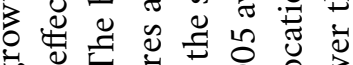

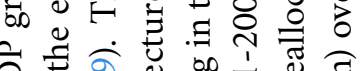

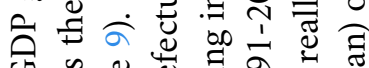

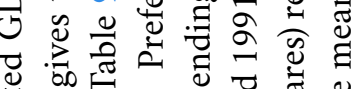

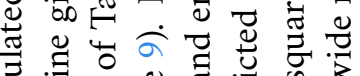

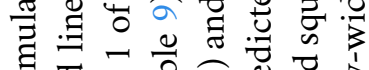

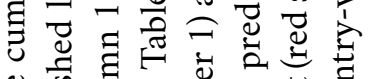

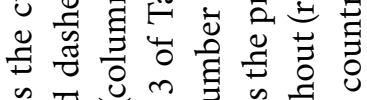

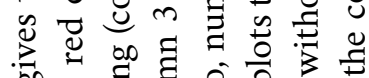
के

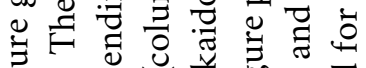
50.

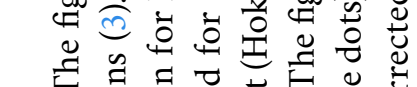

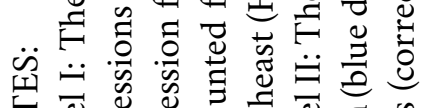

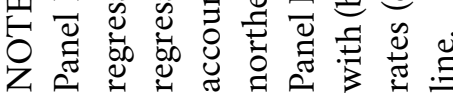


Figure 8: Bond issuance and new loans before and during Japan's lost decade

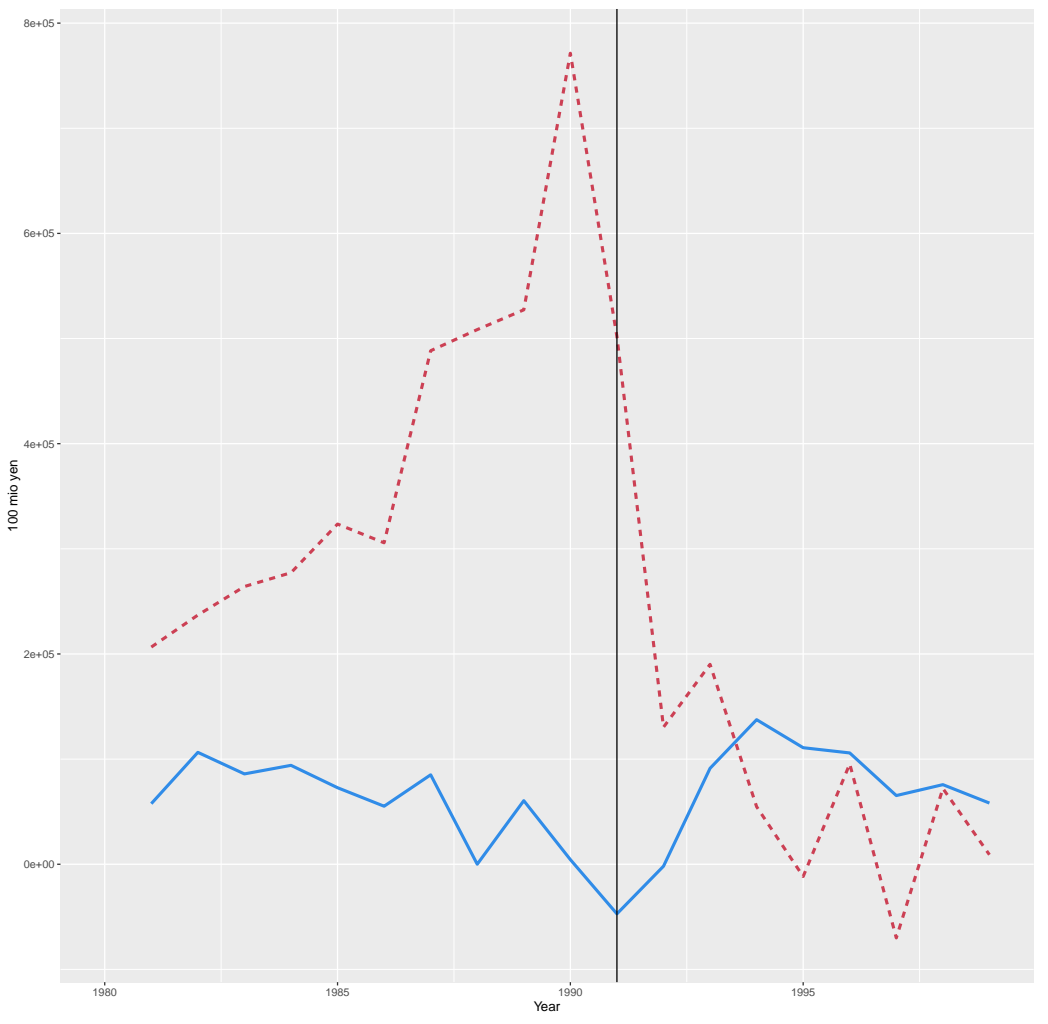

\section{NOTES:}

The figure shows the channels of fund-raising by the domestic non-financial private sector in Japan. The blue solid line gives domestic bond issuance (defined asd domestic issuance by public securities other than shares). The red dashed line gives newly issued loans. Data are from the flow of funds statistics available on the web site of the Bank of Japan.(Data codes FF'FOF_93FFAC021F400 and FF'FOF_93FFAC022F400 respectively). 


\section{A Additional Figures and Tables (for online publication):}


Table A.1: The Credit Reallocation Channel: baseline (OLS) results-Core prefectures dropped

\begin{tabular}{|c|c|c|c|}
\hline & $\begin{array}{c}\text { all banks } \\
\text { (1) }\end{array}$ & $\begin{array}{l}\text { Lendir } \\
\text { integrated banks } \\
\text { (2) } \\
\end{array}$ & $\begin{array}{c}\text { local banks } \\
(3) \\
\end{array}$ \\
\hline $\mathrm{SME}^{k} \times \mathrm{FI}^{k} \mathrm{SHOCK}_{t}$ & $\begin{array}{c}0.75 \\
(0.89)\end{array}$ & $\begin{array}{c}2.58 \\
(1.67)\end{array}$ & $\begin{array}{l}-0.94 \\
(-1.67)\end{array}$ \\
\hline $\mathrm{FI}^{k} \mathrm{SHOCK}_{t}$ & $\begin{array}{l}-0.22 \\
(-1.52)\end{array}$ & $\begin{array}{l}-0.50 \\
(-2.13)\end{array}$ & $\begin{array}{c}0.02 \\
(0.09)\end{array}$ \\
\hline $\mathrm{SME}^{k} \mathrm{SHOCK}_{t}$ & $\begin{array}{l}-0.66 \\
(-1.33)\end{array}$ & $\begin{array}{l}-1.56 \\
(-1.73)\end{array}$ & $\begin{array}{c}0.21 \\
(0.77)\end{array}$ \\
\hline predicted output growth & $\begin{array}{c}0.27 \\
(0.96)\end{array}$ & $\begin{array}{c}0.14 \\
(0.45)\end{array}$ & $\begin{array}{c}0.01 \\
(0.04)\end{array}$ \\
\hline local land price growth & $\begin{array}{c}0.01 \\
(0.47)\end{array}$ & $\begin{array}{c}0.03 \\
(0.77)\end{array}$ & $\begin{array}{l}-0.05 \\
(-0.43)\end{array}$ \\
\hline local land price growth $\times \mathrm{SME}^{k}$ & $\begin{array}{c}0.08 \\
(0.40)\end{array}$ & $\begin{array}{l}-0.01 \\
(-0.05)\end{array}$ & $\begin{array}{c}0.30 \\
(0.46)\end{array}$ \\
\hline Local bank real estate exposure $\times \mathrm{SHOCK}_{t}$ & $\begin{array}{c}0.07 \\
(0.69)\end{array}$ & $\begin{array}{c}0.14 \\
(1.08)\end{array}$ & $\begin{array}{c}0.01 \\
(0.04)\end{array}$ \\
\hline Distance to Yokohama $\times \mathrm{SHOCK}_{t}$ & $\begin{array}{l}-0.00 \\
(-0.96)\end{array}$ & $\begin{array}{l}-0.00 \\
(-0.16)\end{array}$ & $\begin{array}{l}-0.00 \\
(-0.50)\end{array}$ \\
\hline $\begin{array}{l}\text { Observations } \\
\text { Adjusted } R^{2}\end{array}$ & $\begin{array}{l}608 \\
0.59 \\
\end{array}$ & $\begin{array}{l}608 \\
0.80\end{array}$ & $\begin{array}{c}608 \\
0.74\end{array}$ \\
\hline
\end{tabular}

NOTES: The table shows OLS results for our reduced-form specifications (5) $\Delta$ OUTCOME $_{t}^{k}=$ $\left[\alpha_{0} \times \mathrm{SME}^{k} \times \mathrm{FI}^{k}+\alpha_{1} \times \mathrm{FI}^{k}+\alpha_{2} \times \mathrm{SME}^{k}+\boldsymbol{\alpha}_{3}^{\prime} X^{k}\right] \times \mathrm{SHOCK}_{t}+\mu^{k}+\tau_{t}+\boldsymbol{b}^{\prime} Z_{t}^{k}+\nu_{t}^{k}$ where $\Delta \operatorname{OUTCOME}_{t}^{k}$ stands for aggregate prefecture-level lending growth by all banks (column (1)), integrated banks (column (2)) and local banks (column (3)). $\mathrm{SHOCK}_{t}$ is the (negative) land price growth in the core prefectures, $\mathrm{SME}^{k}$ is small-business importance based on the SME share in total employment in prefecture $k, \mathrm{FI}^{k}$ is the measure of regional banking integration, $X^{k}$ and $Z_{t}^{k}$ are vectors of additional controls and $\mu^{k}$ and $\tau_{t}$ are prefecture-fixed and time effects respectively. The sample period is 1980-96. Core prefectures are dropped from the sample. Standard errors are clustered by prefecture and year, t-statistics in parentheses. 
Table A.2: The Credit Reallocation Channel: IV evidence-Core prefectures dropped

\begin{tabular}{|c|c|c|c|}
\hline & $\begin{array}{c}\text { all banks } \\
\text { (1) }\end{array}$ & $\begin{array}{l}\text { Lending } \\
\text { integrated banks } \\
\text { (2) }\end{array}$ & $\begin{array}{c}\text { local banks } \\
\text { (3) }\end{array}$ \\
\hline $\mathrm{SME}^{k} \times \widehat{\mathrm{FI}^{k} \times} \mathrm{SHOCK}_{t}$ & $\begin{array}{c}5.03 \\
(1.46)\end{array}$ & $\begin{array}{c}8.94 \\
(2.67)\end{array}$ & $\begin{array}{c}1.94 \\
(0.36)\end{array}$ \\
\hline $\mathrm{FI}^{k} \widehat{\times \mathrm{SHOCK}_{t}}$ & $\begin{array}{c}-0.93 \\
(-1.56)\end{array}$ & $\begin{array}{l}-1.34 \\
(-2.68)\end{array}$ & $\begin{array}{l}-0.78 \\
(-0.88)\end{array}$ \\
\hline $\mathrm{SME}^{k \times \mathrm{SHOCK}_{t}}$ & $\begin{array}{l}-2.82 \\
(-1.63)\end{array}$ & $\begin{array}{l}-4.75 \\
(-2.79)\end{array}$ & $\begin{array}{l}-1.26 \\
(-0.48)\end{array}$ \\
\hline predicted output growth & $\begin{array}{c}0.27 \\
(0.93)\end{array}$ & $\begin{array}{c}0.13 \\
(0.39)\end{array}$ & $\begin{array}{c}0.02 \\
(0.06)\end{array}$ \\
\hline local land price growth & $\begin{array}{c}0.00 \\
(0.14)\end{array}$ & $\begin{array}{c}0.03 \\
(0.60)\end{array}$ & $\begin{array}{l}-0.07 \\
(-0.66)\end{array}$ \\
\hline local land price growth $\times \mathrm{SME}^{k}$ & $\begin{array}{c}0.12 \\
(0.57)\end{array}$ & $\begin{array}{c}0.02 \\
(0.06)\end{array}$ & $\begin{array}{c}0.36 \\
(0.58)\end{array}$ \\
\hline Local bank real estate exposure $\times \mathrm{SHOCK}_{t}$ & $\begin{array}{c}0.12 \\
(1.00)\end{array}$ & $\begin{array}{c}0.21 \\
(1.63)\end{array}$ & $\begin{array}{c}0.05 \\
(0.27)\end{array}$ \\
\hline Distance to Yokohama $\times \mathrm{SHOCK}_{t}$ & $\begin{array}{l}-0.00 \\
(-0.72)\end{array}$ & $\begin{array}{c}0.00 \\
(0.04)\end{array}$ & $\begin{array}{l}-0.00 \\
(-0.67)\end{array}$ \\
\hline $\begin{array}{l}\text { Observations } \\
\text { Adjusted } \mathrm{R}^{2}\end{array}$ & $\begin{array}{l}608 \\
0.57\end{array}$ & $\begin{array}{l}608 \\
0.80\end{array}$ & $\begin{array}{l}608 \\
0.73\end{array}$ \\
\hline
\end{tabular}

NOTES: The table shows IV results for the specification

$$
\Delta \text { OUTCOME }_{t}^{k}=\alpha_{0} \times \mathrm{SME}^{k} \times \widehat{\mathrm{FI}^{k} \times \mathrm{SHOCK}_{t}}+\alpha_{1} \times \mathrm{FI}^{k} \widehat{\times \mathrm{SHOCK}_{t}}+\alpha_{2} \times \mathrm{SME}^{k} \times \mathrm{SHOCK}_{t}+\mathrm{Controls}
$$

where $\triangle \mathrm{OUTCOME}_{t}^{k}$ is aggregate prefecture-level lending growth for all banks (column (1)), integrated banks (column (2)) and local banks (column (3)). The regression uses SME ${ }^{k} \times \operatorname{SILK}^{k} \times \mathrm{SHOCK}_{t}$ and $\mathrm{SILK}^{k} \times \mathrm{SHOCK}_{t}$ as instruments, where $\operatorname{SILK}^{k}$ is the number of silk filatures per head in prefecture $k$ in 1895 . As before, $\mathrm{SHOCK}_{t}$ is the (negative) land price growth in the core prefectures, $\mathrm{SME}^{k}$ is small-business importance based on the SME share in total employment in prefecture $k, \mathrm{FI}^{k}$ is the measure of regional banking integration, $X^{k}$ and $Z_{t}^{k}$ are vectors of additional controls and $\mu^{k}$ and $\tau_{t}$ are prefecture-fixed and time effects respectively. The sample period is 1980-1996, core prefectures are dropped from the sample. Standard errors are clustered by prefecture and year, t-statistics appear in parentheses. 
Table A.3: Credit Reallocation and Output Growth- OLS and IV results, Core prefectures dropped

Dependent variable is prefecture-level GDP growth

OLS IV

(1)

$\begin{array}{lcc}\mathrm{SME}^{k} \times \mathrm{FI}^{k} \text { SHOCK }_{t} & 0.78 & 2.55 \\ & (0.89) & (1.39) \\ & & \\ \mathrm{FI}^{k} \text { SHOCK }_{t} & -0.16 & -0.43 \\ & (-1.52) & -(1.46) \\ \mathrm{SME}^{k} \text { SHOCK }_{t} & & -1.30 \\ & (-0.41 & (-1.73)\end{array}$

Controls YES YES

$\begin{array}{ll}\text { Observations } \quad 950 & 950\end{array}$

\begin{tabular}{ll} 
Adjusted $\mathrm{R}^{2}$ & 0.66 \\
\hline
\end{tabular}

NOTES: The table shows OLS (column (1))and IV (column (2)) results for our reduced-form specifications (5) $\Delta_{\mathrm{GDP}_{t}^{k}}=$ $\left[\alpha_{0} \times \mathrm{SME}^{k} \times \mathrm{FI}^{k}+\alpha_{1} \times \mathrm{FI}^{k}+\alpha_{2} \times \mathrm{SME}^{k}+\boldsymbol{\alpha}_{3}^{\prime} X^{k}\right] \times \mathrm{SHOCK}_{t}+\mu^{k}+\tau_{t}+$ $\boldsymbol{b}^{\prime} Z_{t}^{k}+\nu_{t}^{k}$ where $\Delta \mathrm{GDP}_{t}^{k}$ stands for aggregate prefecture-level output growth $\mathrm{SHOCK}_{t}$ is the (negative) land price growth in the core prefectures, $\mathrm{SME}^{k}$ is small-business importance based on the SME share in total employment in prefecture $k, \mathrm{FI}^{k}$ is the measure of regional banking integration, $X^{k}$ and $Z_{t}^{k}$ are vectors of additional controls and $\mu^{k}$ and $\tau_{t}$ are prefecture-fixed and time effects respectively. The sample period is 1980-2005. Standard errors are clustered by prefecture and year, t-statistics in parentheses. Core prefectures are dropped from the sample. Controls are the same as in the lending growth regressions in Tables 3 and 4. Coefficients for control variables are not reported. In the IV-regression, $\mathrm{SME}^{k} \times \mathrm{FI}^{k} \mathrm{SHOCK}_{t}$ and $\mathrm{FI}^{k} \mathrm{SHOCK}_{t}$ are instrumented using $\mathrm{SME}^{k} \times \mathrm{SILK}^{k} \mathrm{SHOCK}_{t}$ and $\mathrm{SILK}^{k} \mathrm{SHOCK}_{t}$, as in Table 5 


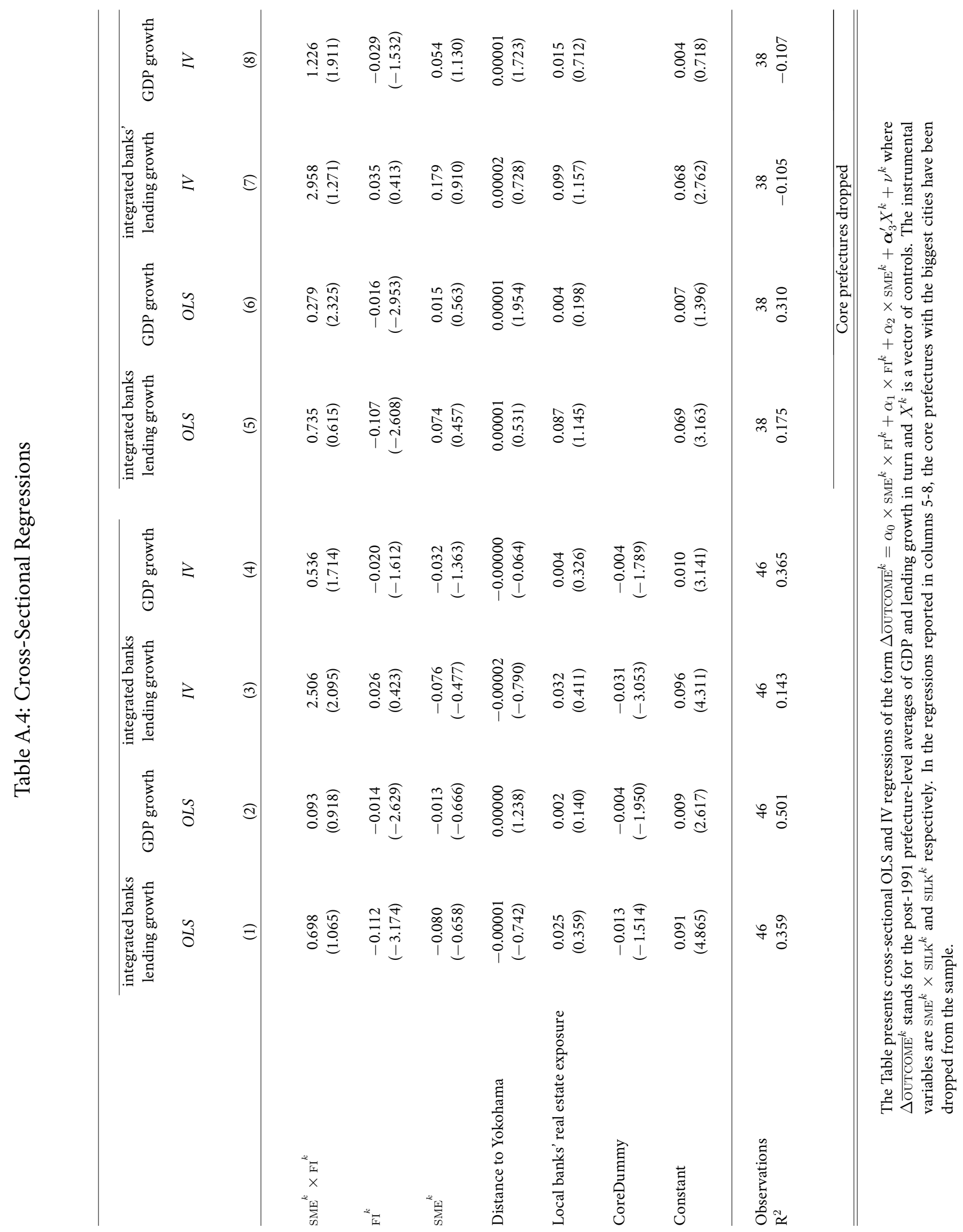




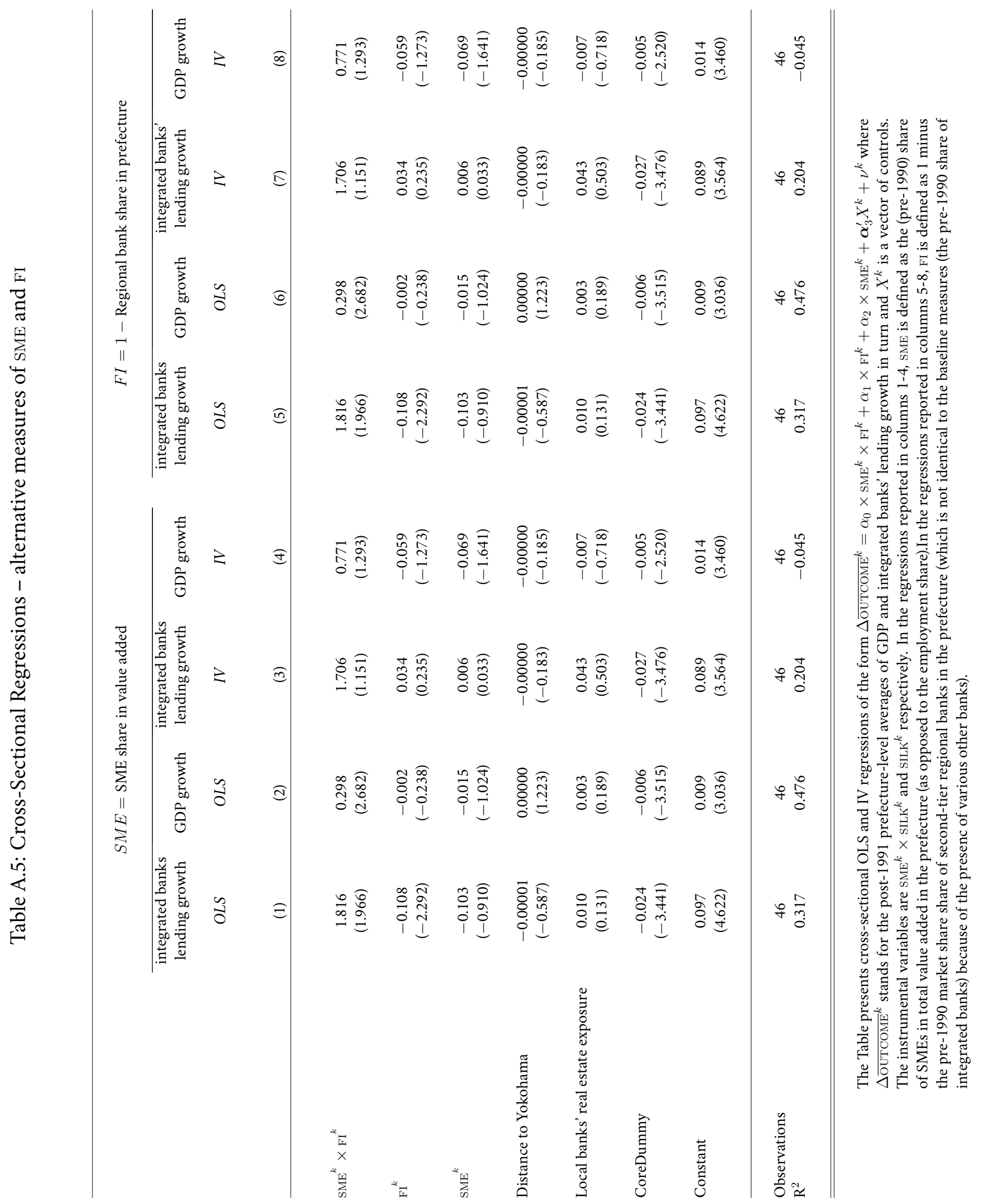




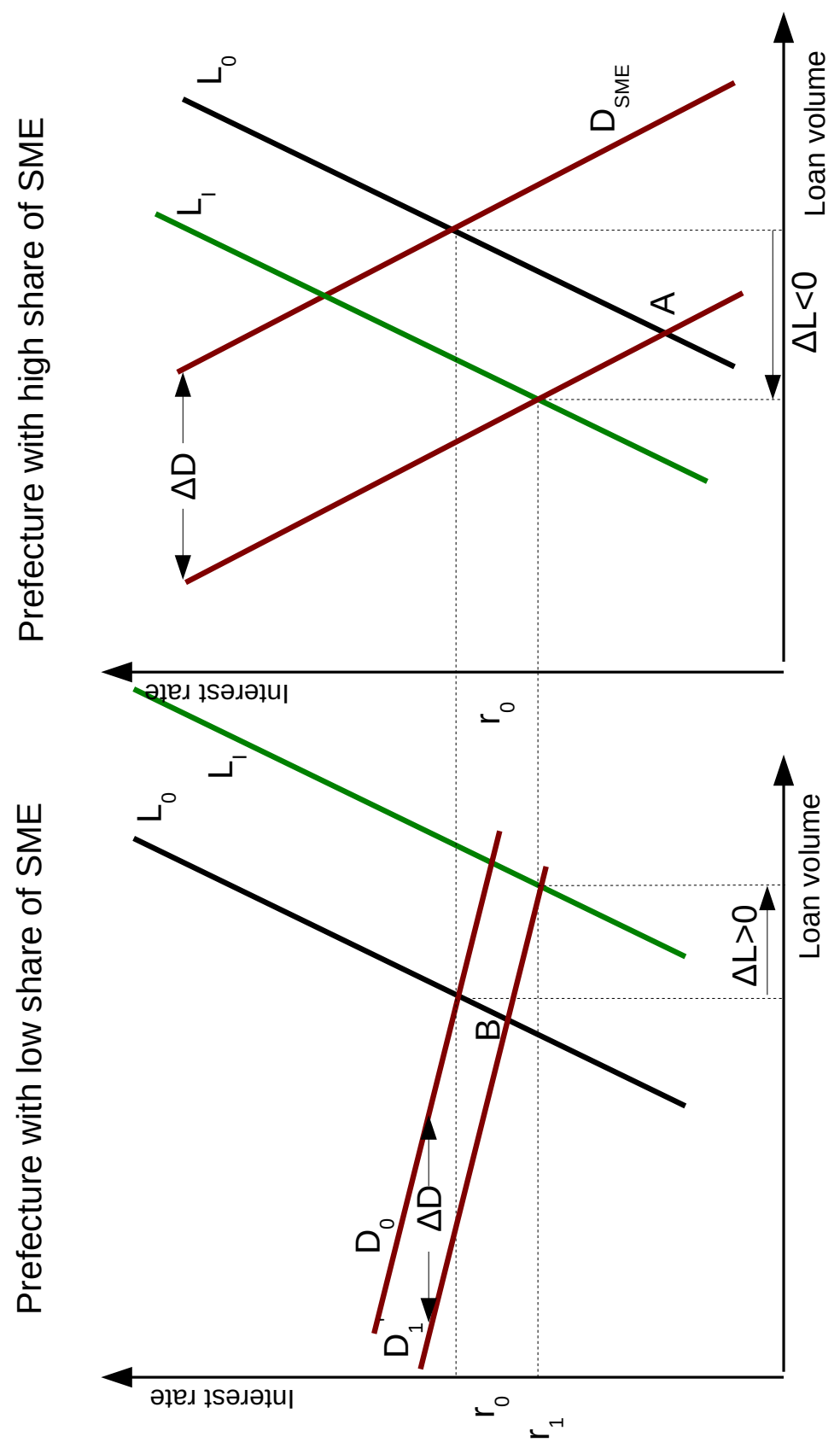

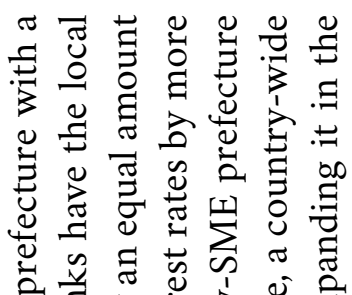

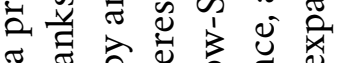
늉ำ

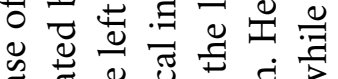
๘ ๑ స

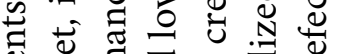

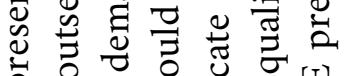
䒕

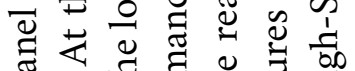

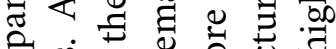

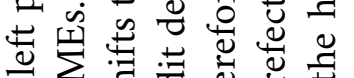

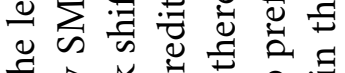

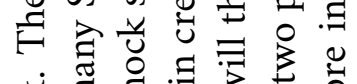

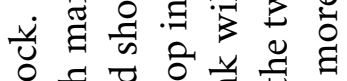
क ర)

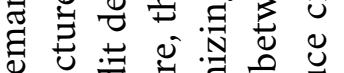
ช

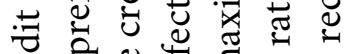
¿ ๑ प

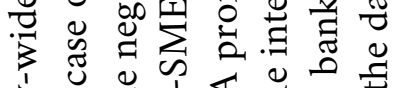

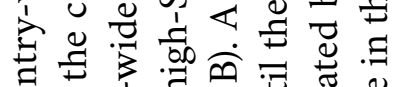

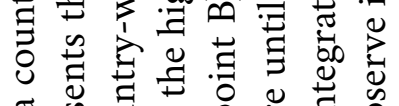
๙ पे

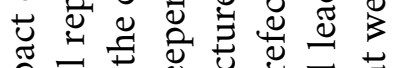

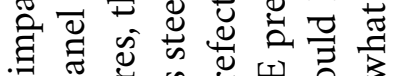

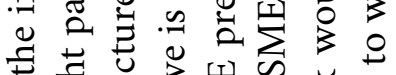
क 氜

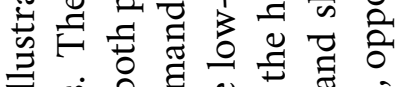
: $\circlearrowleft \sum_{0} \Xi$

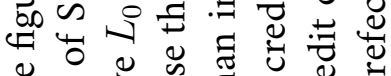

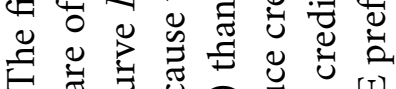

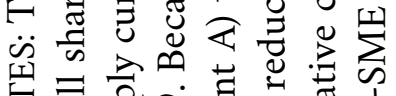

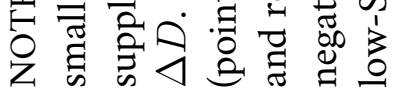

